\title{
Membrane Localization of Membrane Type 5 Matrix Metalloproteinase by AMPA Receptor Binding Protein and Cleavage of Cadherins
}

\author{
Sara Monea, Bryen A. Jordan, Sapna Srivastava, Sunita DeSouza, and Edward B. Ziff \\ Department of Biochemistry, New York University School of Medicine, New York, New York 10016
}

\begin{abstract}
Matrix metalloproteinases (MMPs) have been proposed to remodel the extracellular environment of neurons. Here, we report that the metalloproteinase membrane-type 5 MMP (MT5-MMP) binds to AMPA receptor binding protein (ABP) and GRIP (glutamate receptor interaction protein), two related postsynaptic density (PSD) PDZ (postsynaptic density-95/Discs large/zona occludens-1) domain proteins that target AMPA receptors to synapses. The MT5-MMP C terminus binds ABP PDZ5 and the two proteins coimmunoprecipitated and colocalized in heterologous cells and neurons. MT5-MMP localized in filopodia at the tips of growth cones in young [2-5 din vitro (DIV)] cultured embryonic hippocampal neurons, and at synapses in mature (21 DIV) neurons. Its enrichment in synaptosomes also indicated a synaptic localization in the mature brain. Deletion of the PDZ binding site impaired membrane trafficking of MT5-MMP, whereas exogenous ABP splice forms that are associated either with the plasma membrane or with the cytosol, respectively, colocalized with MT5-MMP in synaptic spines or recruited MT5-MMP to intracellular compartments. We show that endogenous MT5-MMP is found in cultured neurons and brain lysates in a proenzyme form that is activated by furin and degraded by auto-proteolysis. We also identify cadherins as MT5-MMP substrates. These results suggest that ABP directs MT5-MMP proteolytic activity to growth cones and synaptic sites in neurons, where it may regulate axon pathfinding or synapse remodeling through proteolysis of cadherins or other ECM or cell adhesion molecules.
\end{abstract}

Key words: AMPA receptor binding protein; membrane-type 5 matrix metalloproteinase; PDZ domain; neuron; growth cone; synapse; cadherin

\section{Introduction}

Remodeling of neuronal cell junctions is a continuous process in the developing and adult brain. Extension and retraction of dendritic filopodia and attraction and repulsion of growth cones during synaptogenesis require a continuing re-elaboration of cellular membrane interactions (Mueller, 1999; Dunaevsky and Mason, 2003), processes that may serve the acquisition and retention of new information (Maletic-Savatic et al., 1999; Luscher et al., 2000; Toni et al., 2001; Yuste and Bonhoeffer, 2001; Lamprecht and LeDoux, 2004), and require the remodeling of extracellular matrix (ECM) and cell adhesion molecules (Luscher et al., 2000; Cline, 2001).

\footnotetext{
Received Aug. 19, 2005; revised Nov. 29, 2005; accepted Jan. 5, 2006.

This work was supported by National Institutes of Health (NIH) Grant AG13620 (E.B.Z.). S.M. was supported by $\mathrm{NIH}$ Training Grant GM07238, and B.A.J. was supported by NIH Grant K01MH073759. We are grateful to Dr. D. Pei for the full-length MT5-MMP CDNA plasmid and anti-extracellular MT5-MMP antibody, Dr. E. Schuman for the E-cadherin CDNA plasmid, and the Developmental Studies Hybridoma Bank (developed under the auspice of the National Institute of Child Health and Human Development and maintained by the University of lowa Department of Biological Sciences) for monoclonal antibody to SV2 developed by K. M. Buckley.

Correspondence should be addressed to Edward B. Ziff, Department of Biochemistry, New York University School of Medicine, New York, NY 10016. E-mail: edward.ziff@med.nyu.edu.

S. Srivastava's present address: Morgan Stanley, 1585 Broadway, New York, NY 10036.

S. DeSouza's present address: Skirball Institute of Biomolecular Medicine, New York University School of Medicine, New York, NY 10016.

D0I:10.1523/JNEUROSCI.3521-05.2006

Copyright $\odot 2006$ Society for Neuroscience $\quad$ 0270-6474/06/262300-13\$15.00/0
}

Matrix metalloproteinases (MMPs) are extracellular proteinases that degrade components of the ECM, including collagens, glycoproteins, and proteoglycans. They also release growth factors and cleave nonmatrix substrates, such as receptors and cell adhesion molecules (Levi et al., 1996; McCawley and Matrisian, 2001). During CNS development, MMPs facilitate cell migration, myelinogenesis, and axon elongation, mostly through degradation of nonpermissive ECM substrates (Yong et al., 2001). MMPs may also degrade $\beta$-dystroglycan, laminin, and neurotrophins, which regulate neuronal survival and synapse structure (Lee et al., 2001; Costa et al., 2002; Kaczmarek et al., 2002; Chen et al., 2003).

Membrane-type 5 MMP (MT5-MMP) is predominantly expressed in hippocampus and cerebellum, brain regions displaying synaptic plasticity (Jaworski, 2000; Sekine-Aizawa et al., 2001). MT5-MMP may promote axon and dendrite extension (Hayashita-Kinoh et al., 2001; Sekine-Aizawa et al., 2001) and structural remodeling after nerve injury (Komori et al., 2004). However, the role of MT5-MMP in mature neurons, specifically in synaptic plasticity, is unknown.

MT5-MMP is a transmembrane protein consisting of an $\mathrm{N}$-terminal extracellular region containing the catalytic domain, a single transmembrane domain, and a C-terminal 20 aa cytosolic tail that is likely to localize the enzyme (Llano et al., 1999; Pei, 1999; Sekine-Aizawa et al., 2001). In fact, MMP proteolytic activ- 
ity is often restricted to specific sites in the cell membrane (Basbaum and Werb, 1996; Murphy et al., 2000).

Here, we report that MT5-MMP binds two related proteins of the postsynaptic density (PSD), AMPA receptor binding protein $(A B P)$, and glutamate receptor interacting protein (GRIP). The PSD is a matrix of scaffolding proteins that organizes postsynaptic cytoskeletal and signaling peptides (Ziff, 1997). ABP and GRIP interaction with AMPA receptors (Dong et al., 1997; Srivastava et al., 1998) regulates their trafficking and localization (Osten et al., 2000; Fu et al., 2003). ABP and GRIP also interact with ephrins, eph receptors, liprin- $\alpha$, kinesins, and neuronal plakophillinrelated armadillo protein (NPRAP)-cadherin complexes (J. Silverman, L. Lee-Edwards, L. Khatri, W. Lu, and E. B. Ziff, unpublished observations) (Bruckner et al., 1999; Lin et al., 1999; Contractor et al., 2002; Setou et al., 2002; Wyszynski et al., 2002).

Also, we show that both MT5-MMP and ABP/GRIP are localized to the tips of growth cones of developing neurons and to synapses in mature neurons. We present evidence that ABP directs MT5-MMP to these subcellular compartments, where it may cleave cadherin cell adhesion molecules. We suggest that $\mathrm{ABP}$ and GRIP spatially regulate MT5-MMP localization and hence its degradation of ECM or cell adhesion molecules, thereby contributing to synaptogenesis and activity-dependent synaptic remodeling.

\section{Materials and Methods}

Yeast two-hybrid screen. Yeast two-hybrid screening was performed as described previously (Osten et al., 1998; Srivastava et al., 1998). Briefly, the C-terminal 527 residues of ABP-S (amino acids 295-822) were subcloned into the pAS2 vector and used as a bait in the Matchmaker twohybrid system (Clontech, Mountain View, CA) to screen an adult rat brain library in pGAD10 according to the instructions of the manufacturer. The positive clones were further tested by yeast mating assays according to the instructions of the manufacturer (Clontech).

Expression vectors. Full-length murine MT5-MMP cDNA in pCR3.1uni was a gift from Dr. D. Pei (University of Minnesota, Minneapolis, MN) (Pei, 1999).

E-cadherin expression vector was a gift from Dr. E. Schuman (Caltech, Pasadena, CA). Hydrophillic beta-peptide DYKDDDDK-tagged (FLAGtagged) $\mathrm{ABP}$ cDNAs were subcloned in pCMV and pCDNA3.1 vectors (Srivastava et al., 1998). PKC-interacting protein 1 (PICK-1) and GRIP were subcloned in pCDNA3.1. Mutants were made with the QuikChange XL Site-Directed mutagenesis kit (Stratagene, La Jolla, CA) according to the instructions of the manufacturer. FLAG-tagged ABP-L PDZ (PSD95/Discs large/zona occludens-1) domain mutants were constructed in two consecutive mutagenesis cycles, in which two amino acids were mutated in each cycle. Specifically, three ABP-L mutants were made, in which the amino acids ${ }^{416} \mathrm{GFGL}^{419}$ in PDZ4, ${ }^{517} \mathrm{ELGI}^{520}$ in PDZ5, and ${ }^{615} \mathrm{PLGI}^{618}$ in PDZ6, respectively were mutated to alanine. The pairs of primers were as follows: for PDZ4, 5'ggtagtgctctgtggagaccccctcagtgctgcaggcctccagctgcaggggggc $3^{\prime}$ and $5^{\prime}$ 'ggtagtgctctgtggagacccctcagtgctgcagctgcacagctgcaggggggc 3 '; for PDZ5, 5' gttacccaaaaggcgtggtgtggctgcaggcatcaccattagctcggccagcagaaagcg $3^{\prime}$ and $5^{\prime}$ 'gttacccaaaaggcgtggtgtggctgcagctgcaaccattagctcggccagcagaaagcg 3'; for PDZ6, 5'gtggaactgaagcgctatggcggagcagcaggtatcaccatctccggtacagaggaacc $3^{\prime}$ and $5^{\prime}$ 'gtggaactgaagcgctatggcggagcagcagctgcaaccatctccggtacagaggaacc 3 '. To construct catalytically inactive MT5-MMP, the amino acid E252 in the active site of murine MT5-MMP was converted to alanine, using the primer $5^{\prime}$ gccgtgcatgcactgggccat 3 '. Full-length MT5-MMP, $\Delta 3$ deletion mutant lacking the three final amino acids (EWV) and catalytically inactive mutant were generated by PCR and cloned into the XbaI site of pSinRep5 to make Sindbis virus expression vectors.

Glutathione S-transferase-fusion proteins purification and precipitation. To prepare glutathione S-transferase (GST) fusion proteins, the fulllength cytosolic domain of rat MT5-MMP (aa 599-618) or deletion fragments lacking the 3 or 10 final amino acids (aa 599-615 and 599-
608, respectively) were subcloned in-frame at the EcoRI/XhoI sites in pGEX-4T-1 (Amersham Biosciences, Piscataway, NJ). Recombinant GST-MT5 proteins were purified on glutathione Sepharose-4B (Amersham Biosciences) as suggested by the manufacturer, calibrated on Coomassie Brilliant Blue-stained gels, and incubated with in vitro translated ABPs, GRIP, PICK-1, or cell or brain lysates (see below) in $1 \mathrm{ml}$ of $25 \mathrm{~mm}$ HEPES, pH 7.5, $150 \mathrm{~mm} \mathrm{NaCl}$, and 1\% Triton X-100. ABPs, GRIP, and PICK-1 were translated using the TNT Coupled Reticulocyte Translation System (Promega, Madison, WI).

Antibodies. Antibody to the extracellular domain of MT5-MMP (Tyr 125 to Cys538) was obtained from Dr. Pei (Pei, 1999) and Chemicon (Temecula, CA). Antibody to the intracellular domain of MT5-MMP (antibody cytoMT5-MMP; \#2850) was generated by immunization of rabbits with a 16 aa peptide (GPQPVTYYKRPVQEW) from the intracellular domain (aa 598-614) with an extra Cys at the $\mathrm{N}$ terminus that was conjugated to keyhole limpet hemocyanin. Antibodies were affinity purified on a peptide affinity column. Antibody \#303, raised against aa 1027-1043 (QSRRTPGAPGPSSPQMI) at the C terminus of ABP-L, was generated by the same procedure. Antibody to ABP Linker 2 region has been described previously (Srivastava et al., 1998). Monoclonal antibody to synaptic vesicle protein SV2 (SV2), developed by K. M. Buckley, was obtained from the Developmental Studies Hybridoma Bank (University of Iowa, Iowa City, IA). GRIP antibody was generated as described previously (Gabriel et al., 2002). Goat cadherin antibody to the $C$ terminus (C-19) was purchased from Santa Cruz Biotechnology (Santa Cruz, CA). Mouse antibody to the aa $802-819$ of N-cadherin and to GRIP were purchased from BD Transduction Laboratories (Franklin Lakes, NJ).

Cell transfection and immunoprecipitation. Human embryonic kidney 293T (HEK293T) cells were cultured in DMEM supplemented with 10\% FBS and 1\% penicillin-streptomicin. Transfection was performed by the calcium phosphate method with $15 \mu$ g of DNA per $10 \mathrm{~cm}$ dish. Thirty-six hours after transfection, cells were washed with $1 \times$ PBS and solubilized in immunoprecipitation buffer (25 mM HEPES, pH 7.5, $150 \mathrm{~mm} \mathrm{NaCl}$, $1 \%$ Triton X-100) and complete protease inhibitor cocktail (Roche Products, Indianapolis, IN). Immunoprecipitation was performed with $2 \mu \mathrm{g} /$ sample of anti-ABP antibody (\#303) or $1 \mu \mathrm{l} /$ sample anti-extracellular MT5-MMP antibody. Immunoprecipitates were collected with Protein G PLUS-Agarose (Santa Cruz Biotechnology), separated on 8\% SDSPAGE, and analyzed by Western blot.

Immunoprecipitation from cerebellar extracts. Cerebella from adult Sprague Dawley rats were Dounce homogenized in 4 mM HEPES, pH 7.5, and $0.32 \mathrm{M}$ sucrose buffer containing protease inhibitors. The homogenates were clarified by centrifugation at $1000 \mathrm{rpm}$ for $15 \mathrm{~min}$, and the supernatant was collected and spun down at $30,000 \times g$ for $30 \mathrm{~min}$ to yield the $\mathrm{P} 2$ pellet. The $\mathrm{P} 2$ pellet was suspended at $2-3 \mathrm{mg} / \mathrm{ml}$ in ice-cold $10 \mathrm{~mm}$ Tris buffer, $\mathrm{pH}$ 7.4, containing protease inhibitors. One-tenth volume of ice-cold DOC buffer (10\% sodium deoxycholate and $500 \mathrm{~mm}$ Tris- $\mathrm{HCl}, \mathrm{pH}$ 9.0) was added to the $\mathrm{P} 2$ fraction and incubated at $36^{\circ}$ for $30 \mathrm{~min}$, after which Triton X-100 was added to a final concentration of $0.1 \%$. The samples were then dialyzed against ice-cold binding buffer $(50$ mм Tris- $\mathrm{HCl}, \mathrm{pH} 7.4$, and $0.1 \%$ Triton X-100) over night. Unextractable material was pelleted at $37,000 \times g$ for $40 \mathrm{~min}$, and the supernatant was used for immunoprecipitation. Specifically, $\sim 1 \mathrm{mg}$ of the lysate was immunoprecipitated with $2 \mu \mathrm{g} / \mathrm{sample}$ of primary antibody. Immunoprecipitates were collected with Protein G PLUS-Agarose (Santa Cruz Biotechnology), resuspended in SDS sample buffer with $80 \mathrm{~mm}$ DTT, separated on $10 \%$ SDS-PAGE, and analyzed by Western blot.

Western blot and cell surface biotinylation of cultured neurons. Cultured hippocampal or cortical neurons at $3 \times 10^{4} \mathrm{cells} / \mathrm{cm}^{2}$ in $10 \mathrm{~cm}$ poly-Llysine-coated Petri dishes were infected with $50 \mu$ l of MT5-MMP viruses, treated with different inhibitors as specified, and washed twice with cold PBS. Cell extracts were prepared in immunoprecipitation buffer $(20 \mathrm{~mm}$ sodium phosphate, $\mathrm{pH} 7.5,150 \mathrm{~mm} \mathrm{NaCl}, 0.1 \%$ SDS, $1 \% \mathrm{NP}-40,0.5 \%$ sodium deoxycholate) and complete protease inhibitor cocktail (Roche Products), and were analyzed by SDS-PAGE and Western blot. To test the effect of proteinase inhibitors on MT5-MMP activation, cortical neurons were plated at a density of $3 \times 10^{4} \mathrm{cells} / \mathrm{cm}^{2}$. GM6001 (Ilomastat; Chemicon) and decanoyl-Arg-Val-Lys-Arg-chlorometylketone (CMK; Bachem) were added to the culture media at 50 and $25 \mu \mathrm{M}$, respectively. 
The proteosome inhibitor MG-132 (Calbiochem, La Jolla, CA) was added to culture media at $10 \mu \mathrm{M}$. For the biotinylation experiments, washed cells were incubated with $1.5 \mathrm{mg} / \mathrm{ml}$ Sulfo-NHS-SS-Biotin (Pierce, Rockford, IL) in PBS for $30 \mathrm{~min}$ at $4^{\circ} \mathrm{C}$. Nonreacted biotin was quenched with $50 \mathrm{~mm}$ glycine in PBS, and cells were rinsed twice with cold PBS. Cell extracts were prepared in immunoprecipitation buffer $(20$ mu sodium phosphate, $\mathrm{pH} 7.5,150 \mathrm{~mm} \mathrm{NaCl}, 0.1 \%$ SDS, $1 \% \mathrm{NP}-40$, $0.5 \%$ sodium deoxycholate) and complete protease inhibitor cocktail (Roche Products). Biotinylated surface proteins were purified with Ultralink Immobilized NutrAvidin beads (Pierce) and analyzed by SDSPAGE and Western blot. Densitometry of the bands and quantification of surface MT5-MMP were performed using ImageJ software, and $p$ values were determined by standard $t$ test.

Immunocytochemistry. HeLa cells were seeded on glass coverslips and transfected by the calcium phosphate method. Twenty-four hours after transfection, live cells were incubated with anti-MT5-MMP antibody (Pei, 1999) at 1:500 dilution in DMEM $\left(40\right.$ min at $\left.4^{\circ} \mathrm{C}\right)$, washed with $1 \times$ PBS, fixed with $4 \%$ paraformaldehyde (Electron Microscopy Sciences, Fort Washington, PA) in $0.12 \mathrm{M}$ sucrose in PBS (10 min at room temperature), permeabilized with $0.25 \%$ Triton X-100 (10 min at room temperature), blocked in $10 \%$ bovine serum albumin (BSA) in PBS, and then incubated with $0.5 \mu \mathrm{g} / \mathrm{ml} \mathrm{M} 2$ FLAG antibody (Sigma, St. Louis, MO) in $3 \%$ BSA. Cells were then washed three times in $1 \times$ PBS. Secondary antibodies conjugated to rhodamine, fluorescein, or cyanine 5 (Jackson ImmunoResearch, West Grove, PA) were incubated in 3\% BSA for $1 \mathrm{~h}$ at the dilution suggested by the vendor. Images were taken with a Nikon (Tokyo, Japan) PCM 2000 confocal microscope and analyzed using Simple 32 software (Compix, Cranberry Township, PA).

Hippocampal primary cultures and immunofluorescence. Hippocampal primary neurons were prepared as described previously (Osten et al., 1998) and plated at a density of 120,000 cells/well on poly-L-lysine-coated glass coverslips in a six-well plate. Neurons were grown in Neurobasal medium with B27 (Invitrogen, San Diego, CA). After different times in culture, cells were fixed as described above, and endogenous proteins were stained with different antibodies. Anti-cyto-MT5-MMP antibody (\#2850) was used at a concentration of $1.5 \mu \mathrm{g} / \mathrm{ml}$, anti-Synapsin I antibody (Chemicon) at $4 \mu \mathrm{g} / \mathrm{ml}$, anti-microtubule-associated protein 2 (MAP2) antibody (Upstate Biotechnology, Lake Placid, NY) at $5 \mu \mathrm{g} / \mathrm{ml}$, anti-calcium calmodulin-dependent protein kinase II (Boehringer Mannheim, Indianapolis, IN) at $250 \mathrm{ng} / \mathrm{ml}$. ABP antibody to Linker 2 described above was used at a concentration of $0.25 \mu \mathrm{g} / \mathrm{ml}$, and GRIP antibody was used at $1 \mu \mathrm{g} / \mathrm{ml}$.

Sindbis virus infections. Recombinant Sindbis viruses expressing wildtype MT5-MMP or the $\Delta 3$ mutant lacking the three final amino acids, $\mathrm{EWV}$, at the C terminus were generated as described in the Sindbis Expression System manual (Invitrogen). Sindbis viruses expressing ABP-Lgreen fluorescent protein (GFP) and pABP-L-GFP have been previously described (DeSouza et al., 2002; Fu et al., 2003). Infections were performed as described previously (Osten et al., 2000). Briefly, $20 \mu \mathrm{l}$ of viral stock was diluted in $600 \mu \mathrm{l}$ of Neurobasal-B27 medium and added to neurons in each well of a six-well dish for $1 \mathrm{~h}$, after which $1.5 \mathrm{ml}$ of conditioned Neurobasal-B27 medium was added to the wells. Expression was analyzed by antibody staining and confocal microscopy after $18 \mathrm{~h}$.

Brain extracts and subcellular fractionations. Crude forebrains from adult Sprague Dawley rats were homogenized in 25 mM HEPES, pH 7.5, and $150 \mathrm{~mm} \mathrm{NaCl}$ buffer containing protease inhibitors. The homogenates were clarified by centrifugation at $1000 \mathrm{rpm}$ for $5 \mathrm{~min}$, the supernatant was solubilized with $1 \%$ Triton $\mathrm{X}-100$ for $1 \mathrm{~h}$ at $4^{\circ} \mathrm{C}$, and spun at $10,000 \mathrm{rpm}$ for $10 \mathrm{~min}$. The supernatant was incubated in the presence of the different GST-MT5 fusion proteins.

Synaptosomes were purified on sucrose gradients as described previously (Srivastava et al., 1998; Greger et al., 2002). Briefly, brain homogenate was spun at $1000 \times g$ for $10 \mathrm{~min}$; the supernatant (postnuclear fraction) was centrifuged at $9000 \times g$ for $15 \mathrm{~min}$. The supernatant $(\mathrm{cy}-$ tosol) was discarded, and the pellet containing the synaptosomes was resuspended in homogenization buffer and loaded at the top of a threelayer discontinuous sucrose gradient consisting of three layers of 1.2, 1.0, and $0.8 \mathrm{~m}$ sucrose in $10 \mathrm{~mm}$ HEPES, pH 7.4. Purified synaptosomes were collected from the 1.0-1.2 $\mathrm{m}$ interphase, osmotically shocked in hypo-

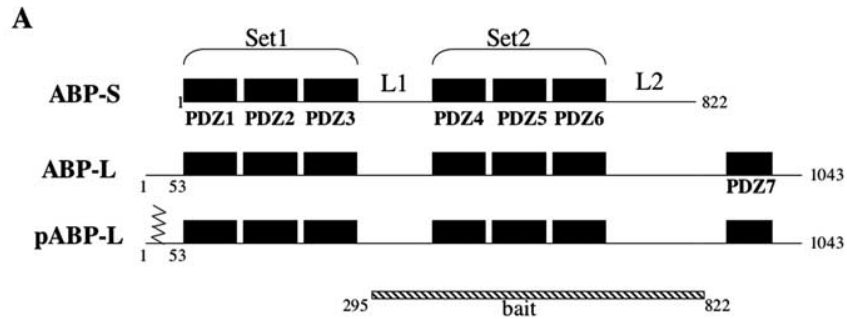

B

\begin{tabular}{|c|c|c|c|c|c|c|}
\hline MT5-MMP & Pro & Catalytic & Hinge & Hemopexin-like & \begin{tabular}{l|l}
$\mathrm{S}$ & $\mathrm{tm}$
\end{tabular} & cyt \\
\hline
\end{tabular}

Figure 1. Schematic representation of different $A B P$ isoforms and MT5-MMP. $\boldsymbol{A}$, Different $A B P$ splice variants are compared. ABP-S, Short form (six PDZ domains); ABP-L, long form (seven PDZ domains); PABP-L, long palmitoylated form (seven PDZ domain and palmitate on Cys 11). $P D Z$ domains are shown as black boxes. The palmitoylation site on Cys 11 in PABP-L is indicated. $\mathrm{L} 1$ and L2, Linker 1 and Linker 2 regions. The ABP fragment used as a bait in the yeast two-hybrid screen is depicted. $\boldsymbol{B}$, Structure of MT5-MMP representing the prodomain (Pro), catalytic domain, hinge region (Hinge), hemopexin-like domain, stem (S), transmembrane (tm), and cytosolic domain (cyt). The CDNA fragments isolated by two-hybrid screen are shown.

tonic buffer to release cytosolic proteins, and centrifuged. The pellet was then solubilized in $25 \mathrm{~mm}$ HEPES, $\mathrm{pH} 7.5,150 \mathrm{~mm} \mathrm{NaCl}$, and 1\% Triton $\mathrm{X}-100$ and spun at $100,000 \times g$ for $15 \mathrm{~min}$. The supernatant was collected as Triton X-100 soluble fraction and the pellet as PSD fraction.

\section{Results}

To understand $\mathrm{ABP}$ contributions to synapse function, we screened for ABP interacting proteins. Three splice variants of ABP have been identified previously (Srivastava et al., 1998; DeSouza et al., 2002). These include a short form (ABP-S) containing six PDZ domains arranged in two sets of three (sets I and II), with each set followed by a linker region (L1 and LII), and two long forms (ABP-L and pABP-L) that, in addition, contain a 52 amino acid $\mathrm{N}$-terminal leader region plus a seventh $\mathrm{C}$-terminal PDZ domain (Fig. 1A). pABP-L contains a unique N-terminal sequence with a palmitoylated cysteine at position 11 (DeSouza et al., 2002). GRIP counterparts to ABP-L and pABP-L have been reported previously (Dong et al., 1997; Yamazaki et al., 2001). To identify ABP interactors, the C-terminal 527 aa of ABP-S, which encompass PDZ domains 4, 5, and 6 (i.e., set II) plus the flanking $\mathrm{L} 1$ and the L2 linker regions, were used as bait for a yeast twohybrid screen of an adult rat brain cDNA library. Two partial cDNA clones of the membrane-type 5 matrix metalloproteinase were isolated.

MT5-MMP consists of an N-terminal extracellular region, a single transmembrane domain, and a short C-terminal cytosolic tail of 20 amino acids (Fig. $1 B$ ). The extracellular portion contains a prodomain at the $\mathrm{N}$ terminus that maintains the enzyme in an inactive form and the removal of which activates the enzyme. This is followed by a catalytic domain with $\mathrm{Zn}^{2+}$ at the active site, a hinge region, a hemopexin-like domain, and a stem region (Llano et al., 1999; Pei, 1999; Sekine-Aizawa et al., 2001). The ABP-interacting clones encoded the hemopexin-like region, stem, transmembrane, and cytosolic domains (aa 335-618) of rat MT5-MMP (Pei, 1999; Sekine-Aizawa et al., 2001).

\section{Binding of ABPs to GST-MT5 fusion proteins}

To verify the interaction between MT5-MMP and ABP, fusions to GST of the 20 amino acid long, full-length cytosolic domain of rat MT5-MMP or truncation mutants of this domain lacking the 
A

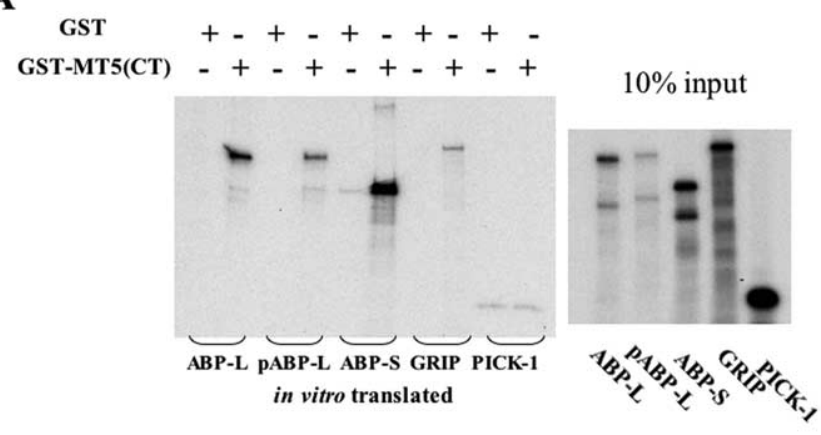

B

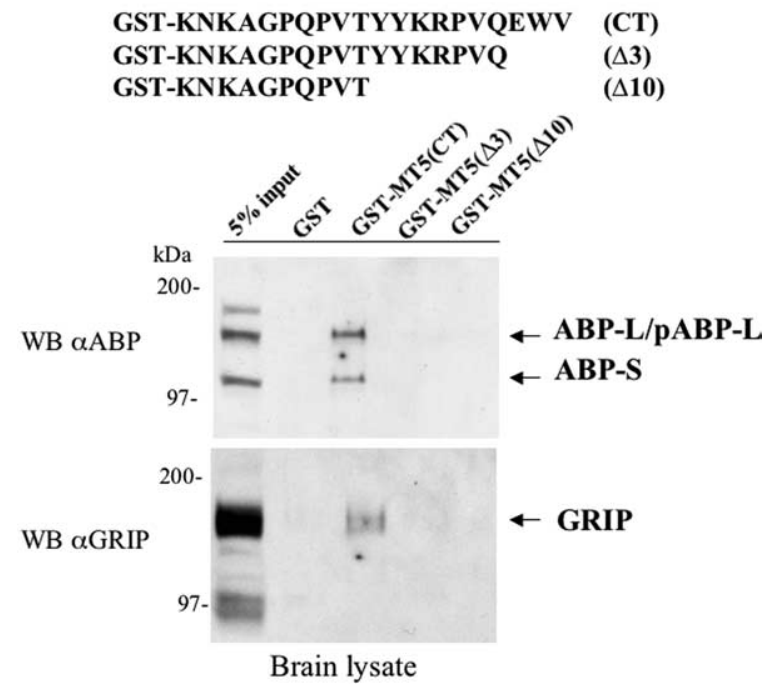

Figure 2. Binding to ABP and GRIP requires MT5-MMP (-terminal amino acids EWV. $\boldsymbol{A}$, Different ABP splice variants (ABP-L, pABP-L, and ABP-S), GRIP, and PICK-1, ${ }^{35}$ S-radiolabeled by translation in vitro in reticulocyte lysates, were incubated with GST alone or GST fused to the full-length, 20 amino acid long, MT5-MMP cytosolic domain [GST-MT(CT)] bound to glutathione agarose beads. The precipitated proteins were resolved by SDS-PAGE and autoradiography. The two gels were electrophoresed in parallel, dried, and exposed on the same film so that they could be compared directly. All ABP splice variants and GRIP bound to the cytosolic domain of MT5-MMP, but not to GST alone, whereas a control PDZ protein, PICK-1, did not bind. B, GSTMT5 fusion proteins containing the full-length MT5-MMP cytosolic domain (CT) or deletion mutants lacking the three $(\Delta 3)$ or $10(\Delta 10)$ C-terminal amino acids were incubated with Triton $X-100$ rat brain lysates. The associated proteins were then analyzed by SDS-PAGE and immunoblotting with specific antibodies to ABP and GRIP. Both short and long ABP forms (ABP-S, ABP-L, and PABP-L) and GRIP bound to the full-length MT5-MMP cytosolic domain but not to deletion mutants missing the 3 or 10 C-terminal amino acids.

three (EWV) or 10 (YYKRPVQEWV) final amino acids were incubated with ${ }^{35} S$-labeled ABP-L, pABP-L, and ABP-S prepared by translation in reticulocyte lysates (Fig. 2A). Cytosolic tails of membrane proteins and receptors often mediate binding to PDZ domains of scaffolding proteins through their three C-terminal residues. ABP and GRIP are proteins containing PDZ domains, and the C-terminal amino acids of MT5-MMP represent a possible PDZ-binding sequence. All three ABP forms bound to the full-length MT5-MMP cytosolic domain GST fusion but not to GST alone. GRIP bound with lower efficiency; however, PICK-1, a PDZ-containing control protein, did not bind, suggesting that the binding to ABP and GRIP was specific. Both the 120 and 98 $\mathrm{kDa}$ forms of $\mathrm{ABP}$ from rat brain lysates, which represent ABP-L together with $\mathrm{pABP}-\mathrm{L}$ and $\mathrm{ABP}-\mathrm{S}$, respectively, bound to the wild-type MT5-MMP cytosolic domain GST-fusion but not to the $\Delta 3$ and $\Delta 10$ truncation mutants (Fig. $2 B$ ). GRIP from brain lysate also bound to the full-length cytosolic domain (Fig. $2 \mathrm{~B}$ ) but more weakly than $\mathrm{ABP}$, as seen for in vitro translated GRIP. We conclude that the three C-terminal residues of the MT5MMP cytosolic tail mediate MT5-MMP binding to both ABP and GRIP. Also, the interaction resembles a PDZ-mediated interaction, because deletion of the PDZ-binding sequence in the cytosolic tail of MT5-MMP prevents the binding.

We analyzed the interaction by incubating lysates of HEK293 cells expressing FLAG epitope-tagged ABP deletion mutants with the MT5-MMP C-terminus GST fusions (Fig. 3A). ABP set II (PDZ4, 5, 6) but not set I (PDZ1, 2, 3) bound to the wild-type C-terminus GST-MT5(CT), indicating that the interaction was specific. The flanking Linker 1 region facilitated the interaction, but the Linker 2 region appeared to have an inhibitory effect on the PDZ-mediated binding. Inhibition by Linker 2 was relieved by the presence of Linker 1 . We conclude that the $\mathrm{C}$ terminus of MT5-MMP binds to PDZ domain(s) of ABP set II and that L1 sequences of $A B P$ may be required for high-affinity binding. To determine the particular ABP PDZ domain(s) involved in MT5MMP binding, mutants with nonfunctional PDZ domains were constructed. Specifically, the four amino acids that generate the carboxylate-binding loop in the hydrophobic pockets of ABP-L PDZ4, PDZ5, and PDZ6 (the so-called "GLGF" motif) were mutated to alanine (respectively, ${ }^{416} \mathrm{GFGL} \rightarrow \mathrm{AAAA}^{419}$, $\left.{ }^{517} \mathrm{ELGI} \rightarrow \mathrm{AAAA}^{520},{ }^{615} \mathrm{PLGI} \rightarrow \mathrm{AAAA}^{618}\right)$. These mutants were then expressed in HEK293T cells and assayed for interaction with the MT5-MMP C-terminus GST fusion. As shown in Figure 3B, the inactivation of PDZ5, but not PDZ4 or PDZ6, greatly decreased the binding of ABP-L to MT5-MMP, suggesting that this PDZ domain is required for MT5-MMP binding. Assays for coimmunoprecipitation of MT5-MMP with ABP deletion mutants (epitope-tagged PDZ4-5-6, PDZ4-5, and PDZ5-6) support this finding. PDZ4 -5 on its own still binds to MT5-MMP, whereas PDZ5-6 can not (Fig. 3C). This is consistent with PDZ5 being the binding site for MT5-MMP and with PDZ4 being an accessory domain, which contribute to the generation of a compact, two PDZ domain structure, PDZ4-5. In this structure, PDZ5 provides the single functional binding site, and PDZ4 stabilizes PDZ5 (Feng et al., 2003).

\section{Coimmunprecipitation and colocalization of $\mathrm{ABP}$ and MT5-MMP}

We confirmed the interaction of MT5-MMP with ABP by demonstrating coimmunoprecipitation and colocalization of these proteins in heterologous cells. We used the murine MT5-MMP (Pei, 1999), the cytosolic domain of which differs from that of the rat protein by a single amino acid, at position -17 (A in mouse; $\mathrm{T}$ in rat). We detected MT5-MMP with an affinity-purified antibody raised against the MT5-MMP cytosolic domain, which recognized the transfected murine protein as a band of $\sim 62 \mathrm{kDa}$ in a Western blot. After coexpression of MT5-MMP and FLAGtagged ABP-L in HEK293T cells, immunoprecipitation of ABP by an antibody recognizing the ABP-L C terminus (\#303) coprecipitated MT5-MMP, as shown by Western blot (Fig. 4A). Conversely, ABP-L was coimmunoprecipitated with MT5-MMP by an antibody against the extracellular domain of MT5-MMP (Fig. $4 B)$. MT5-MMP also coimmunoprecipitated with pABP-L and ABP-S (data not shown).

MT5-MMP independently expressed by transfection in HeLa cells localized at the cell surface (Fig. 4Ci), whereas ABP-L expressed independently formed large dense clusters in the cytoplasm (Fig. 4Cii) (DeSouza et al., 2002; Fu et al., 2003). Strikingly, when the two proteins were coexpressed, ABP-L was recruited to 
the cell membrane (Fig. 4Ciii), where it colocalized with MT5-MMP. The ability of coexpressed MT5-MMP to alter the subcellular localization of ABP-L strongly supports the conclusion that the two proteins can form a complex in heterologous cells.

\section{Expression of MT5-MMP and ABP in brain}

Endogenous ABP is localized in cytosolic clusters in neurons from different brain regions, and it is also found at synapses and in the PSD (Srivastava et al., 1998; Burette et al., 2001). MT5-MMP is also widely expressed in the brain, including in the hippocampus and cerebellum (Jaworski, 2000; Hayashita-Kinoh et al., 2001; Sekine-Aizawa et al., 2001), but its subcellular localization and function in mature neurons are unknown. Western blot analysis of Triton X-100 lysates of cultured cortical neurons and adult rat brain identified MT5-MMP as a major band of $\sim 62$ $\mathrm{kDa}$ (Fig. 5A, $B$ ). The active MT5-MMP species is unstable and rapidly decays by autoproteolysis (Wang et al., 1999; Wang and Pei, 2001). When cells were incubated in the presence of the MMP inhibitor, GM6001 (Ilomastat), a new band of $\sim 58$ $\mathrm{kDa}$ was observed. This suggests that the $62 \mathrm{kDa}$ band is the inactive proenzyme, and the $58 \mathrm{kDa}$ band is the active form produced by proteolytic removal of a peptide of $\sim 10 \mathrm{kDa}$ from the proenzyme $\mathrm{N}$ terminus and stabilized against autoproteolysis by the inhibitor. In heterologous cells, the protease furin was reported to conduct the proteolytic cleavage that activates MT5-MMP in the trans-Golgi network (Wang and Pei, 2001). When the furin inhibitor CMK was added to the culture media together with GM6001, the generation of the active 58 $\mathrm{kDa}$ form was inhibited, suggesting that furin is an MT5-MMP activator in neurons as well (Fig. $5 A$, top).

We biotinylated cell surface protein to determine what form of MT5-MMP was present at the cell surface of neurons. To prevent degradation of the active MT5-MMP form by autoproteolysis, the MMP inhibitor GM6001 was added to the culture medium for $24 \mathrm{~h}$ before biotinylation (see Materials and Methods). As shown in Figure $5 A$ (middle and bottom panels), both the proenzyme and active forms were present at the cell surface. This suggests that not all MT5-MMP produced by the cell is activated intracellularly by furin and that MT5-MMP proenzyme is also found at the cell surface and could be activated by other mechanisms.

As shown in Figure 5B, MT5-MMP was enriched in the synaptosomal fraction of adult rat forebrain, suggesting that, similar to $\mathrm{ABP}$, the metalloproteinase is found at synapses (Srivastava et al., 1998). ABP was found in the Triton X-100 insoluble fraction, which contains PSD proteins. In contrast, MT5-MMP was found in the soluble fraction and was absent from the PSD (Fig. $5 B$, bottom). This differential extraction is consistent with MT5whereas PDZ5- 6 does not.
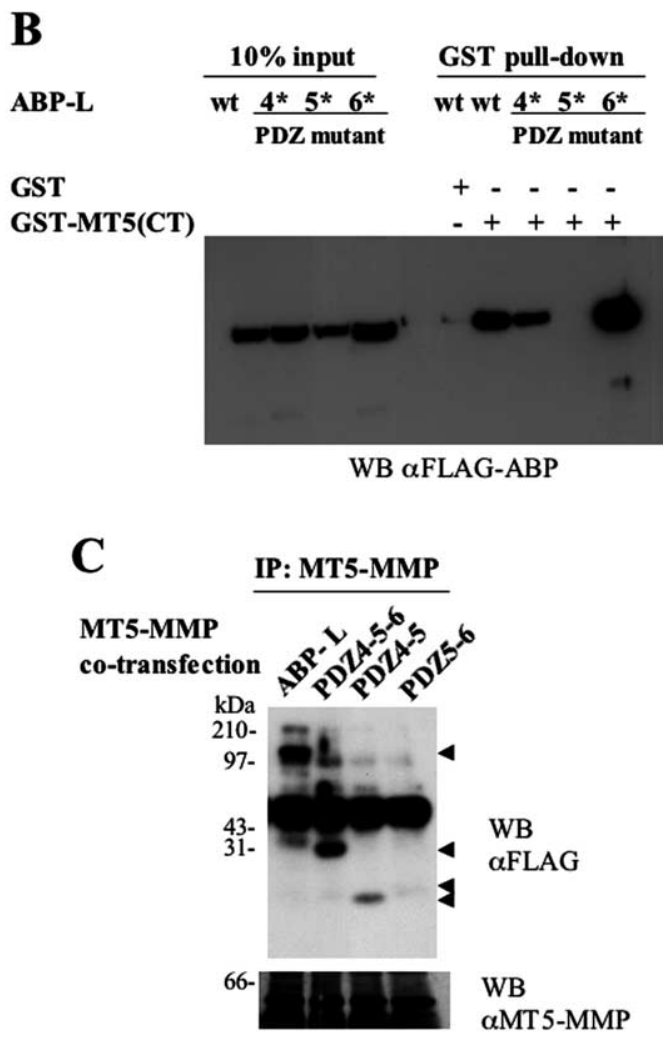

Figure 3. Binding to MT5-MMP is mediated by ABP PDZ5. $A$, Top, Schematic representation of Flag-tagged ABP-L full length and fragments used to determine the MT5-MMP binding domain. Bottom, Triton X-100 lysates of HEK293T cells transfected with indicated Flag-tagged ABP fragments were incubated with GST fused to full-length MT5-MMP cytosolic domain [GTS The smallest fragment still able to bind consisted of the set 2 of PDZ domains (S2), whereas set 1 did not bind. B, ABP-L mutants

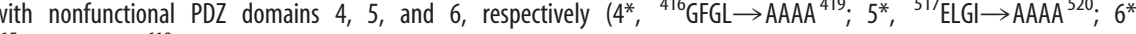
(epitope-tagged full-length ABP-L and isolated PDZ4 -5-6, PDZ4 -5, and PDZ5-6) coexpressed in HEK293T cells were coimmunoprecipitated with an antibody to the extracellular domain of MT5-MMP (aa 125-538) and detected by Western blot by antibodies anti-cytosolic domain of MT5-MMP (anti-cytoMT5-MMP, \#2850; to aa 598-614) and anti-Flag, respectively. Wildtype ABP-L and isolated set 2 of PDZ domains coimmunoprecipitated with MT5-MMP; PDZ4-5 alone still binds to MT5-MMP,

MMP being a membrane protein and ABP associating with the matrix of insoluble proteins at the synapse that form the PSD. Also, MT5-MMP and ABP coimmunoprecipitated from extracts of adult cerebellum (Fig. 5C), indicating their association in vivo.

\section{Subcellular localization}

To confirm the synaptic localization of MT5-MMP, cultured hippocampal neurons [15-20 d in vitro (DIV)] were stained for endogenous MT5-MMP, GRIP, and synaptic markers. MT5-MMP was observed in the cell body and at the plasma membrane of dendrites, where it showed a discrete, punctate staining (Fig. $5 D, E, G)$. To determine whether these puncta represent synapses, we stained with antibodies to the synaptic markers SV2 and PSD95. MT5-MMP colocalized with each of the markers, confirming in mature neurons the synaptic localization that was indicated by enrichment in the synaptosomal fraction. GRIP also showed a similar pattern of distribution in mature neurons, where it colocalized with the synaptic marker SV2 and with MT5-MMP (Fig. $5 F, G)$.

MT5-MMP has been reported in growth cones of DRG neurons and in dendrites of developing Purkinje cells (Hayashita- 
A

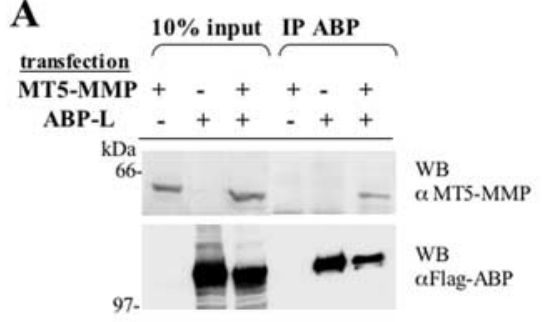

C
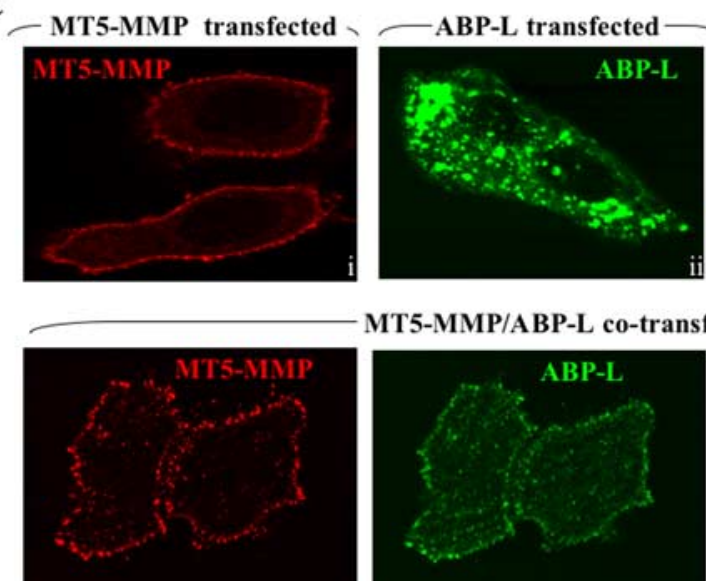

MT5-MMP/ABP-L co-transfected
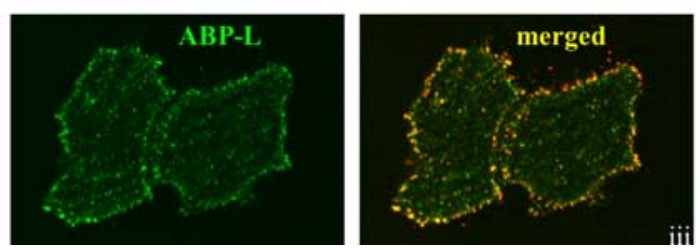

Figure 4. MT5-MMP and ABP-L coimmunoprecipitate and colocalize in heterologous cells. $\boldsymbol{A}, \mathrm{HEK} 293 \mathrm{~T}$ cells were transfected with MT5-MMP and Flag-tagged ABP-L as indicated and immunoprecipitated with an anti-ABP antibody (\#303; to aa 10271043). Expression and precipitation of ABP were detected by immunoblotting with an anti-Flag antibody, whereas expression and coimmunoprecipitation of MT5-MMP were assayed by immunoblotting with an anti-cyto MT5-MMP antibody (\#2850; to aa 598 -614). When expressed together, MT5-MMP and ABP-L were coimmunoprecipitated by the anti-ABP antibody. MT5-MMP was not immunoprecipitated with anti-ABP antibody in the absence of $A B P$, indicating that the binding was specific. $B$, MT5-MMP and ABP-L were also coimmunoprecipitated by an antibody, anti-MT5-MMP extracellular domain (to aa 125-538), when coexpressed in HEK293T cells. As a control, ABP-L was not immunoprecipitated with anti-MT5-MMP antibody in the absence of MT5-MMP. C, HeLa cells were transfected with MT5-MMP alone (i), ABP-L alone (ii), or both MT5-MMP and ABP-L (iii), respectively. MT5-MMP was detected in unpermeabilized cells by a polyclonal antibody to the extracellular domain (red) and ABP-L by mouse anti-FLAG epitope (green) after permeabilization. When expressed alone, ABP-L formed big aggregates inside the cell (ii), whereas MT5-MMP alone was expressed at the cell membrane. Coexpression of MT5-MMP and ABP-L caused the redistribution of ABP-L to the cell membrane, where ABP-L colocalized with MT5-MMP (yellow). This suggests that ABP and MT5-MMP interact in living cells.

Kinoh et al., 2001; Sekine-Aizawa et al., 2001). We asked whether MT5-MMP colocalized with ABP at these sites in developing hippocampal neurons. As shown in Figure 6A, in young hippocampal neurons ( 2 and 5 DIV), MT5-MMP was found in filopodia-like structures at the tips of growth cones in both axons and dendrites, in agreement with the proposed role for the metalloproteinase in the extension of processes and/or synaptogenesis. Axonal growth cones were identified by staining for synapsin 1 , a synaptic vesicle protein that is preferentially localized in the distal portion of axons and growth cones in developing neurons (Fletcher et al., 1991, 1994). We analyzed in parallel the subcellular localization of ABP. ABP was previously localized at mature neuron synapses and in the PSD (Srivastava et al., 1998; DeSouza et al., 2002). In young hippocampal neurons (2 and 5 DIV), ABP was found in the distal portion of extending axons, with a distribution similar to synapsin I (Fig. 6B). As with ABP, GRIP was observed in axonal growth cones of 2 DIV hippocampal neurons (Fig. 6C) (Wyszynski et al., 2002). The finding of endogenous ABP, GRIP, and MT5-MMP in the same cellular compartments is consistent with their interaction and suggests that ABP/GRIP functions in the trafficking or subcellular targeting of MT5-MMP to these sites in neurons.

\section{Study of MT5-MMP and ABP \\ interaction in vivo}

To determine whether the cytosolic tail of the metalloproteinase, which contains the $\mathrm{ABP}$ binding site, is required for MT5MMP plasma membrane localization, we expressed wild-type MT5-MMP or a mutant lacking the three final amino acids $(\Delta 3)$ in hippocampal neurons using Sindbis virus vectors. Surface expression was assayed by Western blot after biotin labeling of surface membrane protein and streptavidin precipitation (see Materials and Methods). Wild-type MT5-MMP was readily detected at the cell surface, whereas the truncated mutant $\Delta 3$, which is unable to bind $\mathrm{ABP}$, was exclusively intracellular (Fig. 7A, top). Densitometry of the bands and quantification of surface MT5-MMP revealed that deletion of the three final amino acids in $\Delta 3$ reduced the amount of the mutant at the cell surface to $\sim 40 \%$ of the level of the wild-type MT5-MMP.

As a control, the surface expression of the AMPA receptor subunit glutamate receptor 1 (GluR1) was not altered by MT5MMP overexpression (Fig. 7A, bottom).

Specific roles for ABP in AMPA receptor (AMPAR) synaptic stabilization and trafficking have been proposed. The palmitoylated form of ABP, pABP-L, is found at the plasma membrane of spines, whereas the unpalmitoylated form, ABP-L, is found in large clusters inside the cell body and dendritic shafts. At both of these subcellular compartments, the ABPs were shown to bind and stabilize AMPARs (DeSouza et al., 2002). This suggests that ABP can target binding proteins differentially depending on its own localization. Therefore, we asked whether ABP can similarly direct the localization of MT5-MMP, either intracellularly or to synapses. When we expressed GFP-tagged pABP-L from a Sindbis virus vector in cultured hippocampal neurons, pABP-L-GFP colocalized with endogenous MT5-MMP in dendritic spines protruding from the dendritic shaft, which was identified by MAP2 staining (Fig. 7B). The putative MT5-MMP/ pABP-L complexes also colocalized with or were in close proximity to the synaptic marker SV2 (Fig. 7D). In contrast, after exogenous expression, the unpalmitoylated ABP-L formed large intracellular clusters within the dendritic shafts. Strikingly, expression of ABP-L altered the subcellular localization of the endogenous metalloproteinase. ABP-L decreased MT5-MMP levels at spines and increased its levels in intracellular compartments (Fig. 7C). A similar result was observed with an ABP fragment containing PDZ set II (data not shown). In addition, after ABP-L expression, the colocalization of MT5-MMP with the synaptic marker SV2 was lost. As shown in Figure 7E, the extent of colocalization between MT5-MMP and SV2 was significantly reduced in neurons infected with ABP-L, and most SV2 did not colocalize extensively with MT5-MMP in these cells (also compare with Fig. 5D). Quantification of this experiment showed that the localization of endogenous MT5-MMP with SV2 was in- 

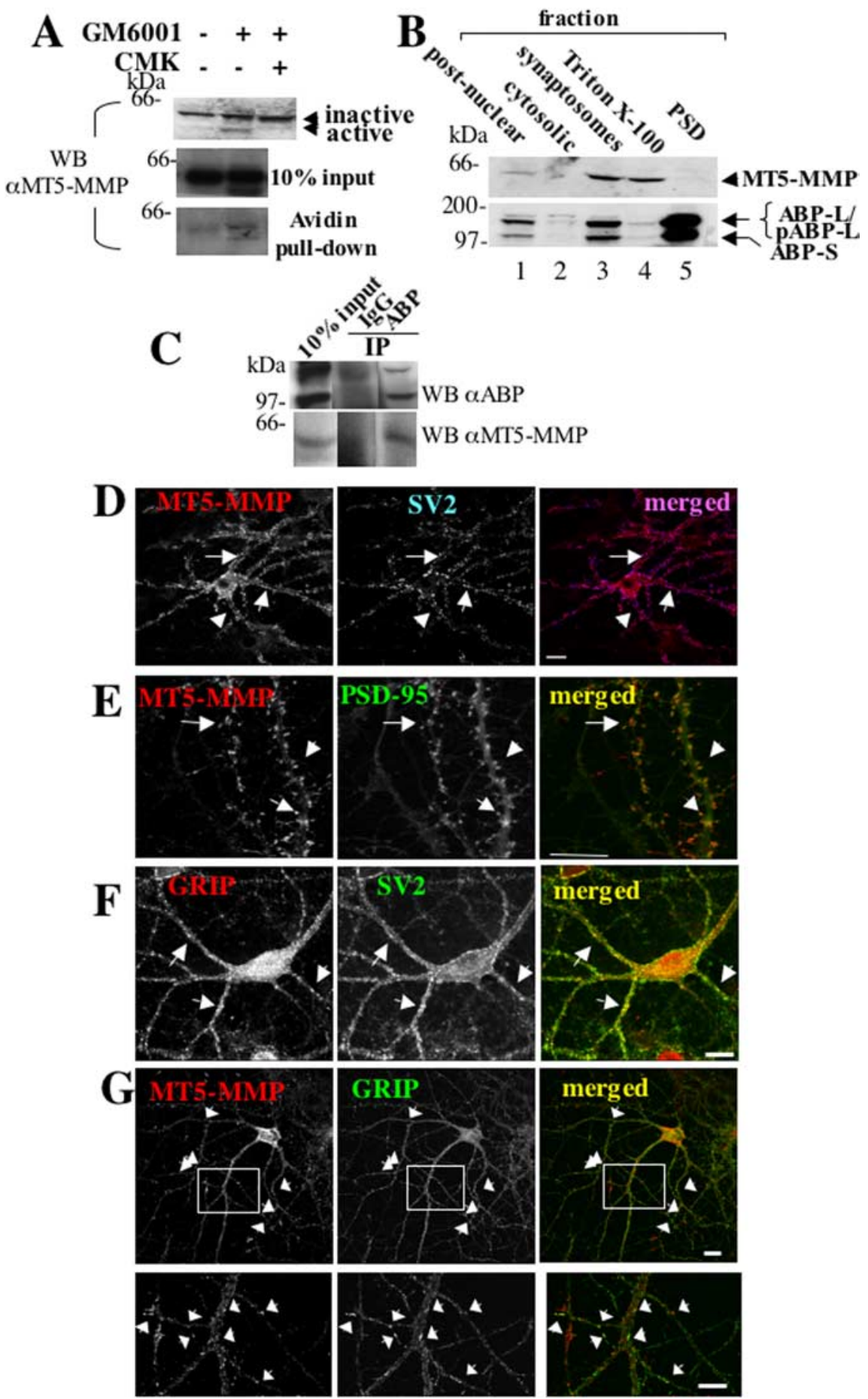

Figure 5. MT5-MMP expression in the brain and in neurons. $\boldsymbol{A}$, Top, To identify MT5-MMP forms expressed by neurons, cultured rat cortical neurons were incubated in culture medium alone, in the presence of an MMP inhibitor (GM6001; Ilomastat; $50 \mu \mathrm{M}$ ) or in the presence of GM6001 and a furin inhibitor (CMK; $25 \mu \mathrm{m})$. Cell extracts were analyzed by Western blotting with an anticytoMT5-MMP antibody (\#2850). Inactive (62 kDa) and active (58 kDa) MT5-MMP forms are indicated by arrows. The active form, generated by furin, is not observed in the presence of the furin inhibitor CMK or in the absence of the MMP inhibitor GM6001, confirming that this form is unstable and rapidly undergo autocatalytic decay. Middle and bottom, Cultured hippocampal neurons were infected with Sindbis virus vectors expressing wild-type MT5-MMP and incubated in the presence or absence of the MMP inhibitor GM6001. At $18 \mathrm{~h}$ after infection, cell surface proteins were biotinylated and purified with avidin as described in Materials and Methods. Total cellular protein (10\% input) and purified surface protein (Avidin pull-down) were analyzed by SDS-PAGE and Western blot with anti-cytoMT5-MMP antibody. The active form of MT5-MMP was observed only in the presence of the inhibitor GM6001. Both the inactive and active forms of MT5-MMP were present at the cell surface. $\boldsymbol{B}$, Brain subcellular fractions (60 $\mu \mathrm{g})$ were obtained as described in Materials and Methods and analyzed by immunoblotting with anti-cytoMT5-MMP antibody (top) or ABP anti-Linker 2 antibody (bottom). Both MT5-MMP and ABP long and short forms copurified and were enriched in the fraction containing synaptosomes (lane 3). MT5-MMP was extracted from the synaptosomal membrane with Triton X-100 (lane 4), whereas ABP was Triton X-100 resistant and was found in the PSD fraction (lane 5). C, Endogenous MT5-MMP creased fourfold in cells expressing pABP-L versus the colocalization in control cells lacking exogenous ABP. In contrast, in cells expressing ABP-L, the colocalization was reduced to 0.6 of that of the control. Interestingly, this result contrasts with the ability of MT5-MMP to recruit ABP-L in heterologous cells to the plasma membrane (Fig. 4Ciii) and suggests that in the targeting of MT5-MMP-ABP complexes in neurons, ABP dominates, whereas in HeLa, the associated membrane protein, MT5-MMP, may dominate. These results indicate that the PDZ binding site of MT5-MMP can contribute to the plasma membrane localization of the enzyme in neurons by interaction with a synaptic scaffolding protein and that ABP can fulfill this targeting function, because interaction of MT5-MMP with pABP-L or ABP-L can localize MT5-MMP in vivo, in cultured neurons. Notably expression of the intracellular peptide, ABP-L, decreases MT5-MMP at synapses and spines, whereas pABP-L favored a synaptic localization. Thus, the cellular location of ABP can determine the location of MT5-MMP.

\section{Function of MT5-MMP in neurons}

MT5-MMP was proposed to degrade purified proteoglycans and gelatin substrates in vitro (Wang et al., 1999) and also to relieve the inhibitory function of proteoglycans during axonal elongation on laminin-coated plates (Hayashita-Kinoh et al., 2001). However, MT5-MMP physiological function and substrates in mature neurons have not yet been investigated.

$\mathrm{ABP}$ resides in a macromolecular complex with NPRAP $(\delta$-catenin) (Silverman, Lee-Edwards, Khatri, Lu, and Ziff, unpublished observations), an armadillo (ARM)

$\leftarrow$

and $A B P$ were coimmunoprecipitated by an antibody, anti$A B P$ Linker 2, from cerebellar lysates as described in Materials and Methods. $\boldsymbol{D}, \boldsymbol{E}$, Immunostaining of primary hippocampal neurons (21 DIV) with a polyclonal antibody to cytoMT5MMP and monoclonal antibodies to different synaptic markers. Scale bars, $20 \mu \mathrm{m}$. Colocalization of endogenous MT5MMP (red) with the synaptic marker SV2 (blue) is shown by pink overlay (D) and PSD-95 (green) by yellow overlay (E). Sites of significant colocalization are indicated by arrows, confirming MT5-MMP synaptic localization. $\boldsymbol{F}$, Colocalization of endogenous GRIP (red) with the synaptic marker SV2 (green) is shown by yellow overlay. Sites of significant colocalization are indicated by arrows, confirming that GRIP was found at the same synaptic compartments as MT5-MMP and ABP. Scale bars, $20 \mu \mathrm{m}$. $\mathbf{G}$, Colocalization of endogenous MT5-MMP (red) with endogenous GRIP (green) is shown by yellow overlay. Sites of significant colocalization are indicated by arrows, and enlargement of the region of interest is shown in the bottom panels. Scale bars, $20 \mu \mathrm{m}$. 

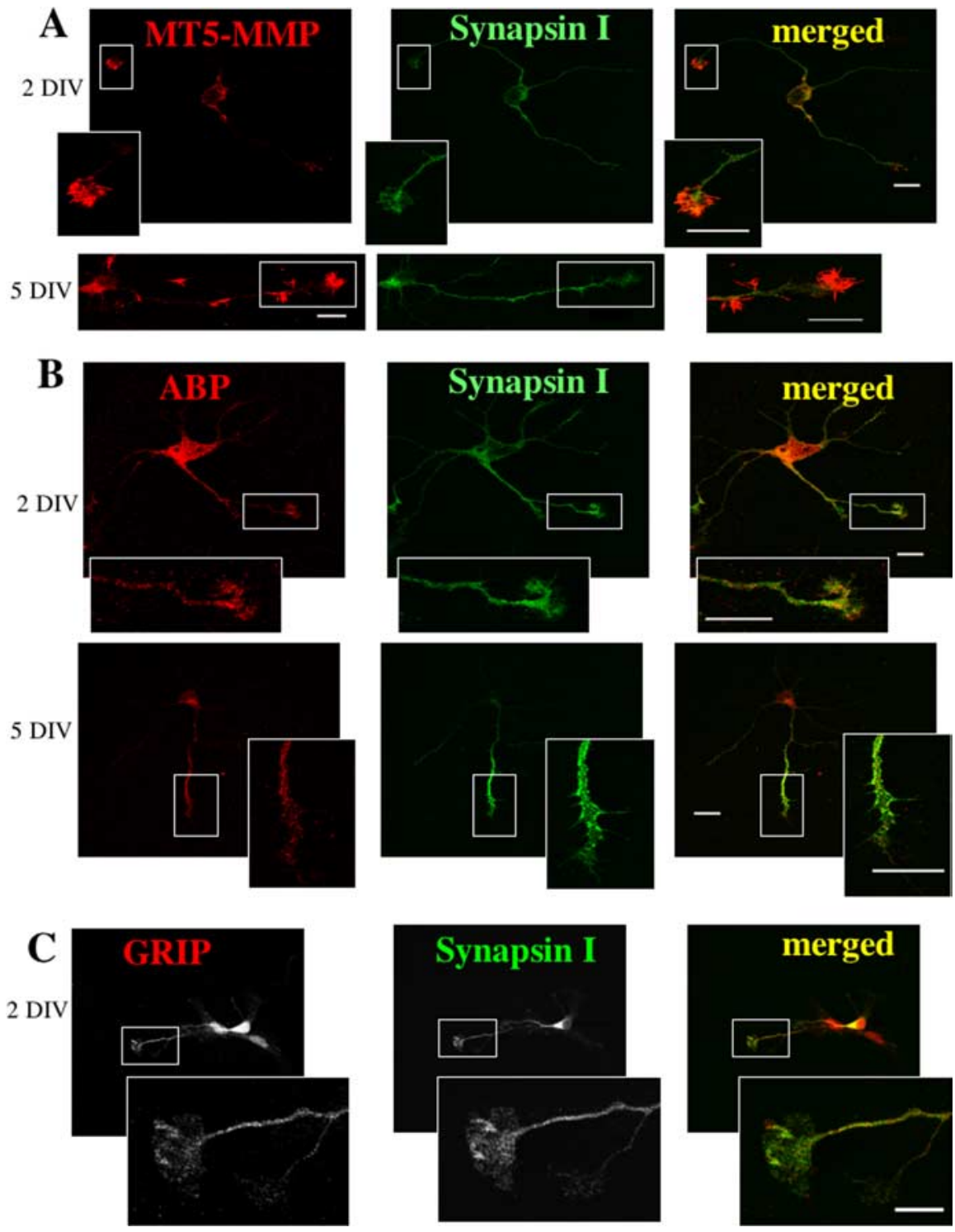

Figure 6. Localization of MT5-MMP and ABP in growth cones of young hippocampal neurons. Immunofluorescence analysis of primary hippocampal neurons at different early developmental stages ( 2 and 5 DIV) labeled with anti-cytoMT5-MMP antibody (red; $\boldsymbol{A}$ ), anti-ABP antibody (red; $\boldsymbol{B}$ ), or anti-GRIP antibody (red; $\boldsymbol{C}$ ) showed MT5-MMP, ABP, and GRIP proteins localized in growth cones, identified by anti-Synapsin I antibody (green; $A, B, C$ ). A higher magnification of the boxed regions is shown. Scale bars, $20 \mu \mathrm{m}$.

repeat protein that binds to cadherins. Modification of cadherins in response to synaptic activity may affect dendritic spine morphogenesis (Tanaka et al., 2000; Togashi et al., 2002). Metalloproteinase-mediated cleavage of cadherins has been reported in other systems (Lochter et al., 1997; Ito et al., 1999; Marambaud et al., 2002), suggesting cadherins as possible substrates for MT5-MMP while bound to ABP at synapses. To determine the mechanisms of cadherin cleavage in neurons, cultured cortical neurons were treated with different proteinase inhibitors (MMP inhibitors and proteasome inhibitors). Western blot analysis of cell lysates of untreated cells using an antibody that recognizes the C-terminal region of $\mathrm{N}$-cadherin showed only the fulllength, unprocessed N-cadherin (Fig. 8A). However, when the proteasome inhibitor MG132 was added to the cell culture medium, a band of $\sim 35 \mathrm{kDa}$ was observed in addition to the fulllength cadherin. This band migrates as expected for the MMPcleaved, membrane-bound fragment containing the cytosolic domain of the cadherin and has been observed by others (Ito et al., 1999; Marambaud et al., 2002). Significantly, this cleavage was inhibited when cells were incubated in the presence of the MMP inhibitor GM6001 (Ilomastat). These results suggest that under physiological conditions, N-cadherins are processed in neurons by MMP and that the resulting cleaved product is degraded by the proteasome intracellular proteolytic pathway.

To determine whether MT5-MMP was the protease responsible for cadherin cleavage in neurons, wild-type MT5MMP or a catalytically inactive mutant were coexpressed with E-cadherin in HEK293T cells. The effect of the MMP expression on cadherin degradation was analyzed by Western blot. As shown in Figure $8 B$, wild-type MT5-MMP but not the inactive mutant was able to generate the $\sim 35 \mathrm{kDa}$ cadherin degradation product.

To determine whether this MT5MMP-mediated cleavage also occurred in neurons, mature cortical neurons were infected with Sindbis virus vectors expressing wild-type MT5-MMP or the catalytically inactive mutant and then incubated in presence of the proteasome inhibitor MG132 for a series of times up to $4 \mathrm{~h}$. The exogenous wild-type MT5-MMP was seen in cell bodies, dendrites, and synapses as shown by colocalization or close proximity with the synaptic marker SV2 (Fig. 8C), and the inactive mutant displayed a similar distribution (data not shown). As observed in Figure $8 D$, the generation of the $\sim 35 \mathrm{kDa}$ cadherin degradation product was delayed in cells expressing the inactive MT5-MMP compared with uninfected cells or cells expressing the wild-type MT5-MMP. Surprisingly, no dramatic increase of the $\sim 35 \mathrm{kDa}$ band was observed after overexpression of wild-type MT5MMP. These results suggest that, in neurons, an MMP activity can cleave $\mathrm{N}$-cadherins and generate an $\sim 35 \mathrm{kDa}$ product that is further degraded by the proteasome proteolytic pathway. This activity may be represented by MT5MMP, given that this enzyme is able to generate the same cadherin band in heterologous cells. These results also raise the possibility that in neurons, a subpopulation of cadherins, possibly those that are synaptic, is accessible to MT5-MMP and are cleaved by this proteinase. Such cleavage of a restricted cadherin population by MT5-MMP would be in agreement with the "dominant-negative" effect of the catalytically inactive MT5-MMP on the generation of the $\sim 35 \mathrm{kDa}$ cadherin degradation product. Expression of wild-type MT5-MMP may not lead to an elevation of active MT5-MMP levels of a greater rate of cadherin cleavage if active MT5-MMP steady state levels are established by an autoproteolysis mechanism, rather than by the rate of MT5-MMP proenzyme expression. 


\section{Discussion}

Here, we report a novel interaction between a brain-specific, membrane-bound matrix metalloproteinase MT5-MMP and the AMPA receptor binding protein ABP. The interaction targets the metalloproteinase to growth cones of neurons during development and to synapse in mature neurons, where it may contribute to synapse formation and remodeling through cleavage of extracellular matrix or cell adhesion molecules. Also, we show that MT5-MMP proteolytic activity is activated by a furinlike convertase and inactivated by autoproteolysis. We also show that MT5-MMP mediates cleavage of cadherins in neurons.

Extracellular proteinases modify cell interactions with the environment during cell migration, growth, and differentiation and must be strictly regulated (Murphy and Gavrilovic, 1999; Vu and Werb, 2000; McCawley and Matrisian, 2001). Proteinase regulation is particularly important in neurons, which require extensive extracellular remodeling during development and synaptic modification but which rely on ECM adhesion for survival (Chen et al., 2003). To limit proteolysis, extracellular proteinases may be spatially confined and active only at those sites where specific substrates require degradation (Basbaum and Werb, 1996; Seeds et al., 1997).

MT5-MMP is a membrane-bound, brain-specific matrix metalloproteinase that participates in axodendritic development and remodeling after nerve injury (Hayashita-Kinoh et al., 2001; SekineAizawa et al., 2001; Komori et al., 2004). It is expressed in brain regions active in plasticity, including the hippocampus and cerebellum, and it may also degrade inhibitory extracellular matrix molecules such as proteoglycans during axonal elongation and synaptogenesis (Hayashita-Kinoh et al., 2001). Our demonstration of MT5MMP in growth cones at early developmental stages and at synapses in mature hippocampal neurons suggests roles for this enzyme in synapse modification.

We show that the localization of MT5MMP depends on the PDZ binding site sequence (EWV), because deletion of this site decreased enzyme levels at the plasma membrane. MT5-MMP binds to PDZ domain set II of ABP. Mutagenesis of the GLGF motif of PDZ5, but not PDZ4 or PDZ6, and deletion of the C-terminal sequence, EWV, of MT5-MMP disrupted the interaction, indicating that it is a PDZ-mediated interaction. We also detect a dependence on PDZ4. It is known, however, from crystallographic studies (Zhang et al., 2001; Feng et al., 2003) that PDZ4 and PDZ5 interact and that PDZ4 stabilizes the function of PDZ5.

A
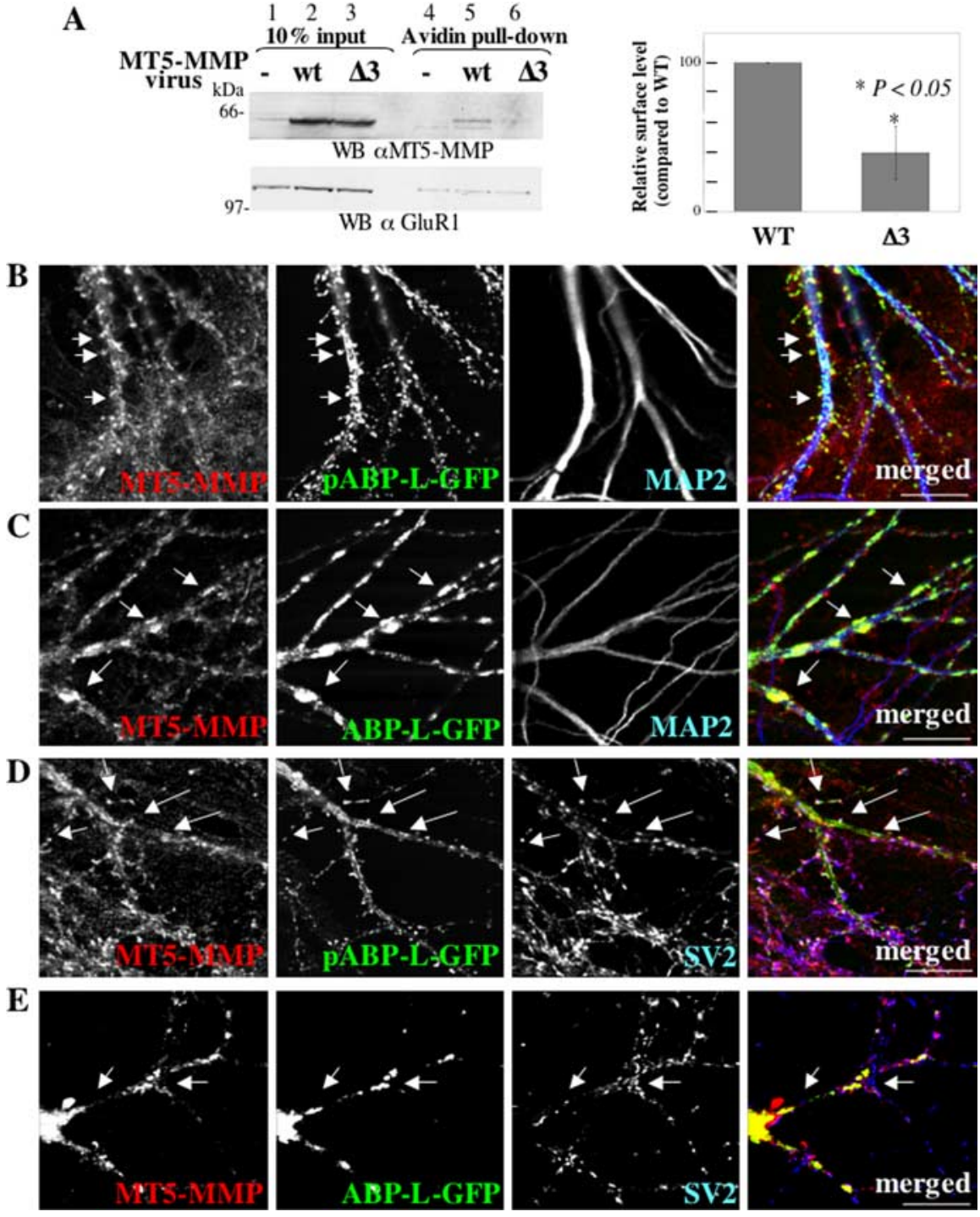

Figure 7. Cellular localization of MT5-MMP dependent in PDZ binding site and ABP isoform. $\boldsymbol{A}$, Cultured hippocampal neurons were infected with Sindbis virus vectors expressing wild-type MT5-MMP or the $\Delta 3$ deletion mutant lacking the three C-terminal amino acids, EWV, previously shown to mediate binding to ABP. At $18 \mathrm{~h}$ after infection, cell surface proteins were biotinylated and purified with avidin as described in Materials and Methods. Total cellular protein (10\% input) and purified surface protein (Avidin pull-down) were analyzed by SDS-PAGE and Western blot with anti-cytoMT5-MMP antibody (top) or anti-GluR1 antibody (bottom). Noninfected neurons showed very low MT5-MMP levels (lane 1) compared with infected cells (lane 2 and 3), which expressed MT5-MMP as a 62 kDa band. Although wild-type and $\Delta 3$ MT5-MMP were expressed at comparable levels in the infected cells (lanes 2 and 3), only wild-type MT5-MMP was expressed at the cell surface (lane 5), and no $\Delta 3$ mutant was found at the cell surface (lane 6). Quantification of surface MT5-MMP was performed by densitometry of the bands. p values were determined by a standard $t$ test $(n=3)$. This suggests that the three ABP-binding amino acids EWV in the MT5-MMP cytosolic tail determine MT5-MMP subcellular localization. As a control, all of the cells analyzed expressed comparable levels of total endogenous GluR1 (lanes 1-3), and no differences were detected in the surface-expressed GluR1 in the different samples (lanes 4-6). $\boldsymbol{B}-\boldsymbol{E}$, Hippocampal neurons at 21 DIV were infected with Sindbis viruses expressing GFP-tagged pABP-L (synaptic form) or ABP-L (intracellular form) (green; $\boldsymbol{B}-\boldsymbol{E}$ ). Eighteen hours after infections, neurons were fixed and costained with antibodies anti-cytoMT5-MMP (red), anti-MAP2 to stain dendritic shafts (blue; $\boldsymbol{B}, \boldsymbol{C}$ ), and anti-SV2 to stain synapses (blue; $\boldsymbol{D}, \boldsymbol{E}$ ). $\boldsymbol{B}, \boldsymbol{D}$, Colocalization of pABP-L (green) and MT5-MMP (red) in synaptic spines protruding from the dendritic shaft (blue) is shown by arrows and yellow overlay in the merged image (B). The colocalization of PABP-L (green) and MT5-MMP (red) with SV2 (blue) is also shown by arrows and white dots (overlay of green, red, and blue dots; $\boldsymbol{D}$ ). $\boldsymbol{C}, \boldsymbol{E}$, Virally expressed unpalmitoylated ABP-L (green) formed intracellular aggregates inside the dendritic shafts $(\boldsymbol{C})$ that did not colocalize with SV2 $(\boldsymbol{E})$. Interestingly, MT5-MMP was recruited in these intracellular compartments, where it colocalized with ABP-L (yellow overlay in Cand $\boldsymbol{E}$, merged pictures). Colocalization of MT5-MMP and SV2 was dramatically reduced $(\boldsymbol{E})$. Arrows show SV2-labeled synapses (blue) that do not show any MT5-MMP (red staining).

Both MT5-MMP and ABP were found at the tips of growth cones at early developmental stages (2-7 DIV) and at synapses in mature neurons, where MT5-MMP colocalized with synaptic markers and GRIP. The splice variant of ABP affected MT5-MMP subcellular 


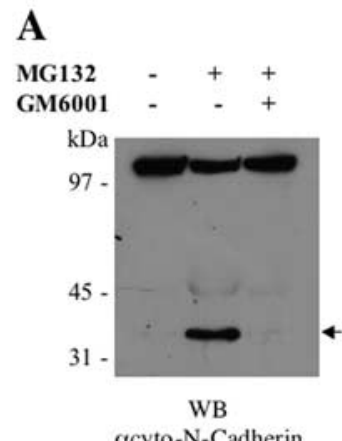

acyto-N-Cadherin

C
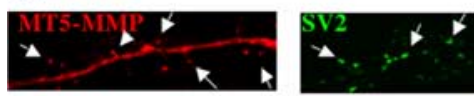

D
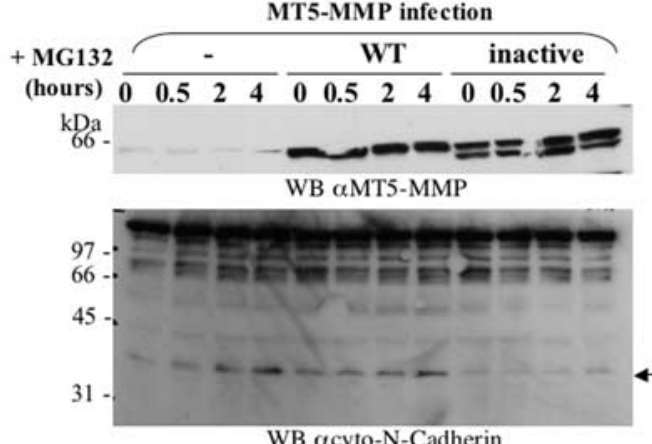

WB $\alpha$ cyto-N-Cadherin

45 WB $\alpha$ tubulin

Figure 8. MT5-MMP-mediated cleavage of cadherins. $\boldsymbol{A}$, Cultured cortical neurons were treated with the proteosome inhibitor MG132 (10 $\mu \mathrm{M}$ ) and the MMP inhibitor GM1006 (Ilomastat; $50 \mu \mathrm{m})$ for $16 \mathrm{~h}$ as indicated, and then cell lysates $(70 \mu \mathrm{g})$ were analyzed by SDS-PAGE and Western blot with an antibody to the intracellular domain of $\mathrm{N}$-cadherin. In the presence of the proteasome inhibitor MG132, a cadherin fragment of $\sim 35 \mathrm{kDa}$ was observed, the generation of which was inhibited by the MMP inhibitor GM1006. This suggests that, in neurons, cadherins are processed by MMP activity to a $\sim 35 \mathrm{kDa}$ fragment that is rapidly degraded by the proteosome proteolytic pathway. B, HEK293T cells were transfected with E-cadherin, wild-type MT5MMP, or a catalytically inactive mutant as indicated. Lysates $(50 \mu \mathrm{g})$ were analyzed by SDSPAGE and Western blot with antibodies to the intracellular domain of MT5-MMP (top) and $\mathrm{N}$-cadherin (bottom). Wild-type MT5-MMP but not the catalytically active mutant generated a cadherin band of $\sim 35 \mathrm{kDa}$ similar to the MMP-generated band in neurons, suggesting that MT5-MMP is the proteolytic activity responsible for cadherin cleavage in physiological conditions. C, Cultured hippocampal neurons were infected with Sindbis virus vector expressing wild-type MT5-MMP and, after $18 \mathrm{~h}$ of infection, fixed, permeabilized, and labeled with anticytoMT5-MMP antibody (red) and anti-SV2 antibody (green). Detection by immunofluorescence showed that MT5-MMP was localized in dendrites and synapses. D, Cultured cortical neurons were infected with Sindbis virus vectors expressing wild-type MT5-MMP or the catalytically inactive mutant for $12 \mathrm{~h}$ and then incubated in the presence of the proteosome inhibitor MG132 for the time indicated. Triton X-100 lysates were assayed by SDS-PAGE and Western blot with different antibodies. Top, MT5-MMP expression is tested by Western blot with anticytoMT5-MMP. Although cells infected with wild-type MT5-MMP only showed the inactive MT5-MMP form, cells infected with the catalytically inactive mutant also showed the active MT5-MMP form, because autoproteolytic decay was inhibited. Middle, Western blot of cell lysates stained with an antibody anti-cytoN-Cadherin showing the kinetics of generation of the $\sim 35 \mathrm{kDa}$ band after overexpression of MT5-MMP (wild-type or catalytically inactive mutant). Overexpression of the catalytically inactive mutant showed a dominant-negative effect by delaying the generation of the cadherin cleavage product, suggesting that MT5-MMP can be the proteolytic activity responsible for the cleavage in neurons. Bottom, Western blot with antitubulin antibody showed that the expression levels of tubulin were the same in all of the samples analyzed. localization. The palmitoylated ABP form, which is found at plasma membrane and spines, directed MT5-MMP to spine heads, whereas the unpalmitoylated ABP form, which is intracellular, directed endogenous MT5-MMP to intracellular compartments. The enrichment of MT5-MMP in synaptosomes, which also contain ABP, also supports a synaptic localization of MT5-MMP. MT5-MMP binds another PDZ domain protein, Mint-3, which may regulate MT5MMP trafficking in heterologous cells (Wang et al., 2004). Mint-3 is expressed at low levels in the brain (Okamoto and Sudhof, 1998), and another protein such as Mint-2 or unpalmitoylated ABP/GRIP could fulfill this function in neurons. The related GRIP protein functions in microtubule transport of EphB2 in dendrites (Hoogenraad et al., 2005). In HeLa cells, MT5-MMP directed unpalmitoylated ABP-L to the cell membrane, suggesting altered targeting mechanisms in heterologous cells. Other mechanisms in addition to palmitoylation, such as interaction with the synaptic cytoskeleton, could anchor ABP at synapses. ABP binds to NPRAP, an ARM repeat protein that binds to cadherins (Silverman, Lu, Lee-Edwards, Khatri, and Ziff, unpublished observations). This interaction could tether MT5-MMP-ABP complexes in close proximity to cadherins, consistent with the capacity of MT5-MMP for cadherin degradation.

Other proteinases contribute to remodeling during neuronal development and activity-dependent synaptic plasticity associated with learning and memory (Seeds et al., 1997; Madani et al., 1999; Shiosaka and Yoshida, 2000; Nicole et al., 2001; Tomimatsu et al., 2002; Wright et al., 2002; Pawlak et al., 2003). The serine proteinase $\mathrm{tPA}$ is regulated by synaptic activity and contributes to LTP, axonal elongation, formation of new synapses, and neuronal remodeling (Qian et al., 1993; Gualandris et al., 1996; Huang et al., 1996; Baranes et al., 1998; Madani et al., 1999; Neuhoff et al., 1999). Although the mechanisms are still incompletely understood, they could involve degradation of ECM substrates such as laminin (Chen and Strickland, 1997; Chen et al., 2003), proteoglycans, (Wu et al., 2000), or receptors such as the NMDA receptor (Nicole et al., 2001).

At present, only a few MMPs have been directly associated functionally with synaptic plasticity (Kaczmarek et al., 2002; Dzwonek et al., 2004). MMP-9 expression is increased in the mouse hippocampus during learning and memory acquisition (Wright et al., 2003) and is regulated in the hippocampus by synaptic activity during dendritic remodeling (Zhang et al., 1998; Szklarczyk et al., 2002). MMP inhibitors also protect hippocampal neurons against kainate-induced excitotoxicity and affects LTP, sprouting and synaptogenesis (Reeves et al., 2003), whereas recombinant MMP-9 induces neuronal death (Jourquin et al., 2003). MMP-9 activation by S-nitrosylation can induce neuronal apoptosis ( $\mathrm{Gu}$ et al., 2002). At the neuromuscular junction, MMP-3 degrades the heparin sulfate proteoglycan agrin (VanSaun and Werle, 2000).

MMPs and plasminogen activators often act together in a proteolytic cascade to degrade different ECM components (Mignatti and Rifkin, 1993, 1996), raising the possibility that in brain, MMPs may function with tPA and plasmin. Both tPA and plasmin can regulate MMP-9 activity (Wang et al., 2003).

Here, we report that cleavage by a furin-like convertase activates MT5-MMP and that cadherins are substrates for MT5MMP in neurons. A furin-like convertase was shown to activate exogenous MT5-MMP in Madin-Darby canine kidney cells (Wang and Pei, 2001). We observed that treatment of cultured neurons with the metalloproteinase inhibitor Ilomastat generated an MT5-MMP band migrating like the active form of the enzyme, generated by cleavage of the "pro"-domain from the 
full-length enzyme. Because the production of this form was blocked by the furin inhibitor CMK cleavage by a furin-like convertase may convert the proform of MT5-MMP to the active form. Because the active form is stabilized by the MMP inhibitor Ilomastat, it may be degraded by autoproteolysis, as occurs in heterologous cells (Wang and Pei, 2001). Observation of both the inactive proenzyme MT5-MMP form and the active form at the cell surface suggests that MT5-MMP is activated at the neuron cell surface by other proteinases, such as serine proteinases, which contribute to synaptic plasticity and activate MMPs (Lijnen, 2001; Lo et al., 2002). Working at the cell surface, MT5-MMP could degrade ECM molecules or cell-adhesion molecules at synapses, perhaps activating other enzymes such as MMP-2, which could extend the range of substrates (Giannelli et al., 1997).

Synaptic structures are maintained, in part, through interactions between molecules in the presynaptic and postsynaptic membranes, including cadherins and other adhesion proteins (Yamagata et al., 2003). ABP is also linked to cell adhesion complexes through binding to NPRAP ( $\delta$-catenin), which in turn binds to cadherins (Silverman, Lu, Lee-Edwards, Khatri, and Ziff, unpublished observations). Cadherins contribute to synaptic plasticity and can determine spine shape and morphology (Bozdagi et al., 2000; Tanaka et al., 2000; Kiss et al., 2001; Huntley et al., 2002; Togashi et al., 2002; Okamura et al., 2004). MMPs cleave cadherins in epithelial cells during their conversion to a malignant, invasive phenotype (Lochter et al., 1997). MMPs can cleave next to the transmembrane region to release the extracellular domain, whereas the membrane-bound fragment is degraded by the intracellular proteolytic pathway (Ito et al., 1999). MMPs working with $\gamma$-secretase can disassemble adherens junctions by cleavage of E-cadherins (Marambaud et al., 2002). Here, we report an MT5-MMP-mediated cleavage of cadherins in both heterologous cells and neurons. MMP activity generated a $~ 35$ $\mathrm{kDa}$ cadherin C-terminal peptide in heterologous cells, the molecular weight of which is consistent with a cleavage product containing the transmembrane and cytosolic domains, as was observed by others (Ito et al., 1999; Marambaud et al., 2002).

In neurons, overexpression of the catalytically inactive MT5MMP exerted a dominant-negative effect, slowing the kinetics of generation of this peptide. Although overexpression of wild-type MT5-MMP did not effect the generation of this cadherin cleavage product, overexpression of MT5-MMP may not lead to an increase in its net proteolytic activity. Indeed, MT5-MMP has a short half-life and is rapidly degraded by autoproteolysis (Wang et al., 1999). Thus, autoproteolysis may prevent elevation of the level of overexpressed active enzyme, whereas the catalytically inactive mutant could exert the observed dominant-negative effect. Alternatively, only a limited subpopulation of cadherins may be accessible to the enzyme and undergo the observed MMPmediated cleavage, limiting the effects of overexpression of wildtype MT5-MMP while allowing the inactive mutant to replace endogenous enzyme and inhibit cadherin cleavage.

MMPs also cleave cell surface receptors (Levi et al., 1996; McCawley and Matrisian, 2001), and proteolysis may regulate NMDA and AMPA receptor activity (Bi et al., 1996; Chan and Mattson, 1999; Gingrich et al., 2000; Lu et al., 2001; Nicole et al., 2001). The association of MT5-MMP with ABP and GRIP, peptides that bind AMPA receptors, suggests mechanisms of synaptic regulation involving neurotransmitter receptors, PDZcontaining proteins, matrix metalloproteinases, and cell adhesion molecules.

\section{References}

Baranes D, Lederfein D, Huang YY, Chen M, Bailey CH, Kandel ER (1998) Tissue plasminogen activator contributes to the late phase of LTP and to synaptic growth in the hippocampal mossy fiber pathway. Neuron 21:813-825.

Basbaum CB, Werb Z (1996) Focalized proteolysis: spatial and temporal regulation of extracellular matrix degradation at the cell surface. Curr Opin Cell Biol 8:731-738.

Bi X, Chang V, Molnar E, McIlhinney RA, Baudry M (1996) The C-terminal domain of glutamate receptor subunit 1 is a target for calpain-mediated proteolysis. Neuroscience 73:903-906.

Bozdagi O, Shan W, Tanaka H, Benson DL, Huntley GW (2000) Increasing numbers of synaptic puncta during late-phase LTP: $\mathrm{N}$-cadherin is synthesized, recruited to synaptic sites, and required for potentiation. Neuron 28:245-259.

Bruckner K, Pablo Labrador J, Scheiffele P, Herb A, Seeburg PH, Klein R (1999) EphrinB ligands recruit GRIP family PDZ adaptor proteins into raft membrane microdomains. Neuron 22:511-524.

Burette A, Khatri L, Wyszynski M, Sheng M, Ziff EB, Weinberg RJ (2001) Differential cellular and subcellular localization of AMPA receptorbinding protein and glutamate receptor-interacting protein. J Neurosci 21:495-503.

Chan SL, Mattson MP (1999) Caspase and calpain substrates: roles in synaptic plasticity and cell death. J Neurosci Res 58:167-190.

Chen ZL, Strickland S (1997) Neuronal death in the hippocampus is promoted by plasmin-catalyzed degradation of laminin. Cell 91:917-925.

Chen ZL, Indyk JA, Strickland S (2003) The hippocampal laminin matrix is dynamic and critical for neuronal survival. Mol Biol Cell 14:2665-2676.

Cline HT (2001) Dendritic arbor development and synaptogenesis. Curr Opin Neurobiol 11:118-126.

Contractor A, Rogers C, Maron C, Henkemeyer M, Swanson GT, Heinemann SF (2002) Trans-synaptic Eph receptor-ephrin signaling in hippocampal mossy fiber LTP. Science 296:1864-1869.

Costa S, Planchenault T, Charriere-Bertrand C, Mouchel Y, Fages C, Juliano S, Lefrancois T, Barlovatz-Meimon G, Tardy M (2002) Astroglial permissivity for neuritic outgrowth in neuron-astrocyte cocultures depends on regulation of laminin bioavailability. Glia 37:105-113.

DeSouza S, Fu J, States BA, Ziff EB (2002) Differential palmitoylation directs the AMPA receptor-binding protein ABP to spines or to intracellular clusters. J Neurosci 22:3493-3503.

Dong H, O’Brien RJ, Fung ET, Lanahan AA, Worley PF, Huganir RL (1997) GRIP: a synaptic PDZ domain-containing protein that interacts with AMPA receptors. Nature 386:279-284.

Dunaevsky A, Mason CA (2003) Spine motility: a means towards an end? Trends Neurosci 26:155-160.

Dzwonek J, Rylski M, Kaczmarek L (2004) Matrix metalloproteinases and their endogenous inhibitors in neuronal physiology of the adult brain. FEBS Lett 567:129-135.

Feng W, Shi Y, Li M, Zhang M (2003) Tandem PDZ repeats in glutamate receptor-interacting proteins have a novel mode of PDZ domainmediated target binding. Nat Struct Biol 10:972-978.

Fletcher TL, Cameron P, De Camilli P, Banker G (1991) The distribution of synapsin I and synaptophysin in hippocampal neurons developing in culture. J Neurosci 11:1617-1626.

Fletcher TL, De Camilli P, Banker G (1994) Synaptogenesis in hippocampal cultures: evidence indicating that axons and dendrites become competent to form synapses at different stages of neuronal development. J Neurosci 14:6695-6706.

Fu J, deSouza S, Ziff EB (2003) Intracellular membrane targeting and suppression of Ser 880 phosphorylation of glutamate receptor 2 by the linker I-set II domain of AMPA receptor-binding protein. J Neurosci 23:7592-7601.

Gabriel R, de Souza S, Ziff EB, Witkovsky P (2002) Association of the AMPA receptor-related postsynaptic density proteins GRIP and ABP with subsets of glutamate-sensitive neurons in the rat retina. J Comp Neurol 449:129-140.

Giannelli G, Falk-Marzillier J, Schiraldi O, Stetler-Stevenson WG, Quaranta $\mathrm{V}$ (1997) Induction of cell migration by matrix metalloprotease-2 cleavage of laminin-5. Science 277:225-228.

Gingrich MB, Junge CE, Lyuboslavsky P, Traynelis SF (2000) Potentiation of NMDA receptor function by the serine protease thrombin. J Neurosci 20:4582-4595. 
Greger IH, Khatri L, Ziff EB (2002) RNA editing at arg607 controls AMPA receptor exit from the endoplasmic reticulum. Neuron 34:759-772.

Gu Z, Kaul M, Yan B, Kridel SJ, Cui J, Strongin A, Smith JW, Liddington RC, Lipton SA (2002) S-nitrosylation of matrix metalloproteinases: signaling pathway to neuronal cell death. Science 297:1186-1190.

Gualandris A, Jones TE, Strickland S, Tsirka SE (1996) Membrane depolarization induces calcium-dependent secretion of tissue plasminogen activator. J Neurosci 16:2220-2225.

Hayashita-Kinoh H, Kinoh H, Okada A, Komori K, Itoh Y, Chiba T, Kajita M, Yana I, Seiki M (2001) Membrane-type 5 matrix metalloproteinase is expressed in differentiated neurons and regulates axonal growth. Cell Growth Differ 12:573-580.

Hoogenraad CC, Milstein AD, Ethell IM, Henkemeyer M, Sheng M (2005) GRIP controls dendrite morphogenesis by regulating EphB receptor traffiking. Nat Neurosci 8:906-915.

Huang YY, Bach ME, Lipp HP, Zhuo M, Wolfer DP, Hawkins RD, Schoonjans L, Kandel ER, Godfraind JM, Mulligan R, Collen D, Carmeliet P (1996) Mice lacking the gene encoding tissue-type plasminogen activator show a selective interference with late-phase long-term potentiation in both Schaffer collateral and mossy fiber pathways. Proc Natl Acad Sci USA 93:8699-8704.

Huntley GW, Gil O, Bozdagi O (2002) The cadherin family of cell adhesion molecules: multiple roles in synaptic plasticity. Neuroscientist 8:221-233.

Ito K, Okamoto I, Araki N, Kawano Y, Nakao M, Fujiyama S, Tomita K, Mimori T, Saya H (1999) Calcium influx triggers the sequential proteolysis of extracellular and cytoplasmic domains of E-cadherin, leading to loss of beta-catenin from cell-cell contacts. Oncogene 18:7080-7090.

Jaworski DM (2000) Developmental regulation of membrane type-5 matrix metalloproteinase (MT5-MMP) expression in the rat nervous system. Brain Res 860:174-177.

Jourquin J, Tremblay E, Decanis N, Charton G, Hanessian S, Chollet AM, Le Diguardher T, Khrestchatisky M, Rivera S (2003) Neuronal activitydependent increase of net matrix metalloproteinase activity is associated with MMP-9 neurotoxicity after kainate. Eur J Neurosci 18:1507-1517.

Kaczmarek L, Lapinska-Dzwonek J, Szymczak S (2002) Matrix metalloproteinases in the adult brain physiology: a link between c-Fos, AP-1 and remodeling of neuronal connections? EMBO J 21:6643-6648.

Kiss JZ, Troncoso E, Djebbara Z, Vutskits L, Muller D (2001) The role of neural cell adhesion molecules in plasticity and repair. Brain Res Brain Res Rev 36:175-184.

Komori K, Nonaka T, Okada A, Kinoh H, Hayashita-Kinoh H, Yoshida N, Yana I, Seiki M (2004) Absence of mechanical allodynia and Abeta-fiber sprouting after sciatic nerve injury in mice lacking membrane-type 5 matrix metalloproteinase. FEBS Lett 557:125-128.

Lamprecht R, LeDoux J (2004) Structural plasticity and memory. Nat Rev Neurosci 5:45-54.

Lee R, Kermani P, Teng KK, Hempstead BL (2001) Regulation of cell survival by secreted proneurotrophins. Science 294:1945-1948 .

Levi E, Fridman R, Miao HQ, Ma YS, Yayon A, Vlodavsky I (1996) Matrix metalloproteinase 2 releases active soluble ectodomain of fibroblast growth factor receptor 1. Proc Natl Acad Sci USA 93:7069-7074.

Lijnen HR (2001) Plasmin and matrix metalloproteinases in vascular remodeling. Thromb Haemost 86:324-333.

Lin D, Gish GD, Songyang Z, Pawson T (1999) The carboxyl terminus of B class ephrins constitutes a PDZ domain binding motif. J Biol Chem 274:3726-3733.

Llano E, Pendas AM, Freije JP, Nakano A, Knauper V, Murphy G, Lopez-Otin C (1999) Identification and characterization of human MT5-MMP, a new membrane-bound activator of progelatinase a overexpressed in brain tumors. Cancer Res 59:2570-2576.

Lo EH, Wang X, Cuzner ML (2002) Extracellular proteolysis in brain injury and inflammation: role for plasminogen activators and matrix metalloproteinases. J Neurosci Res 69:1-9.

Lochter A, Galosy S, Muschler J, Freedman N, Werb Z, Bissell MJ (1997) Matrix metalloproteinase stromelysin-1 triggers a cascade of molecular alterations that leads to stable epithelial-to-mesenchymal conversion and a premalignant phenotype in mammary epithelial cells. J Cell Biol 139:1861-1872.

Lu X, Wyszynski M, Sheng M, Baudry M (2001) Proteolysis of glutamate receptor-interacting protein by calpain in rat brain: implications for synaptic plasticity. J Neurochem 77:1553-1560.

Luscher C, Nicoll RA, Malenka RC, Muller D (2000) Synaptic plasticity and dynamic modulation of the postsynaptic membrane. Nat Neurosci 3:545-550.

Madani R, Hulo S, Toni N, Madani H, Steimer T, Muller D, Vassalli JD (1999) Enhanced hippocampal long-term potentiation and learning by increased neuronal expression of tissue-type plasminogen activator in transgenic mice. EMBO J 18:3007-3012.

Maletic-Savatic M, Malinow R, Svoboda K (1999) Rapid dendritic morphogenesis in CA1 hippocampal dendrites induced by synaptic activity. Science 283:1923-1927.

Marambaud P, Shioi J, Serban G, Georgakopoulos A, Sarner S, Nagy V, Baki L, Wen P, Efthimiopoulos S, Shao Z, Wisniewski T, Robakis NK (2002) A presenilin-1/gamma-secretase cleavage releases the E-cadherin intracellular domain and regulates disassembly of adherens junctions. EMBO J 21:1948-1956.

McCawley LJ, Matrisian LM (2001) Matrix metalloproteinases: they're not just for matrix anymore! Curr Opin Cell Biol 13:534-540.

Mignatti P, Rifkin DB (1993) Biology and biochemistry of proteinases in tumor invasion. Physiol Rev 73:161-195.

Mignatti P, Rifkin DB (1996) Plasminogen activators and matrix metalloproteinases in angiogenesis. Enzyme Protein 49:117-137.

Mueller BK (1999) Growth cone guidance: first steps towards a deeper understanding. Annu Rev Neurosci 22:351-388.

Murphy G, Gavrilovic J (1999) Proteolysis and cell migration: creating a path? Curr Opin Cell Biol 11:614-621.

Murphy G, Knauper V, Atkinson S, Gavrilovic J, Edwards D (2000) Cellular mechanisms for focal proteolysis and the regulation of the microenvironment. Fibrinolysis Proteolysis 14:165-174.

Neuhoff H, Roeper J, Schweizer M (1999) Activity-dependent formation of perforated synapses in cultured hippocampal neurons. Eur J Neurosci 11:4241-4250.

Nicole O, Docagne F, Ali C, Margaill I, Carmeliet P, MacKenzie ET, Vivien D, Buisson A (2001) The proteolytic activity of tissue-plasminogen activator enhances NMDA receptor-mediated signaling. Nat Med 7:59-64.

Okamoto M, Sudhof TC (1998) Mint 3: a ubiquitous mint isoform that does not bind to munc18-1 or -2. Eur J Cell Biol 77:161-165.

Okamura K, Tanaka H, Yagita Y, Saeki Y, Taguchi A, Hiraoka Y, Zeng LH, Colman DR, Miki N (2004) Cadherin activity is required for activityinduced spine remodeling. J Cell Biol 167:961-972.

Osten P, Srivastava S, Inman GJ, Vilim FS, Khatri L, Lee LM, States BA, Einheber S, Milner TA, Hanson PI, Ziff EB (1998) The AMPA receptor GluR2 C terminus can mediate a reversible, ATP-dependent interaction with NSF and alpha- and beta-SNAPs. Neuron 21:99-110.

Osten P, Khatri L, Perez JL, Kohr G, Giese G, Daly C, Schulz TW, Wensky A, Lee LM, Ziff EB (2000) Mutagenesis reveals a role for ABP/GRIP binding to GluR2 in synaptic surface accumulation of the AMPA receptor. Neuron 27:313-325.

Pawlak R, Magarinos AM, Melchor J, McEwen B, Strickland S (2003) Tissue plasminogen activator in the amygdala is critical for stress-induced anxiety-like behavior. Nat Neurosci 6:168-174.

Pei D (1999) Identification and characterization of the fifth membrane-type matrix metalloproteinase MT5-MMP. J Biol Chem 274:8925-8932.

Qian Z, Gilbert ME, Colicos MA, Kandel ER, Kuhl D (1993) Tissueplasminogen activator is induced as an immediate-early gene during seizure, kindling and long-term potentiation. Nature 361:453-457.

Reeves TM, Prins ML, Zhu J, Povlishock JT, Phillips LL (2003) Matrix metalloproteinase inhibition alters functional and structural correlates of deafferentation-induced sprouting in the dentate gyrus. J Neurosci 23:10182-10189.

Seeds NW, Siconolfi LB, Haffke SP (1997) Neuronal extracellular proteases facilitate cell migration, axonal growth, and pathfinding. Cell Tissue Res 290:367-370.

Sekine-Aizawa Y, Hama E, Watanabe K, Tsubuki S, Kanai-Azuma M, Kanai Y, Arai H, Aizawa H, Iwata N, Saido TC (2001) Matrix metalloproteinase (MMP) system in brain: identification and characterization of brainspecific MMP highly expressed in cerebellum. Eur J Neurosci 13:935-948.

Setou M, Seog DH, Tanaka Y, Kanai Y, Takei Y, Kawagishi M, Hirokawa N (2002) Glutamate-receptor-interacting protein GRIP1 directly steers kinesin to dendrites. Nature 417:83-87.

Shiosaka S, Yoshida S (2000) Synaptic microenvironments-structural plasticity, adhesion molecules, proteases and their inhibitors. Neurosci Res 37:85-89.

Srivastava S, Osten P, Vilim FS, Khatri L, Inman G, States B, Daly C, DeSouza 
S, Abagyan R, Valtschanoff JG, Weinberg RJ, Ziff EB (1998) Novel anchorage of GluR2/3 to the postsynaptic density by the AMPA receptorbinding protein ABP. Neuron 21:581-591.

Szklarczyk A, Lapinska J, Rylski M, McKay RD, Kaczmarek L (2002) Matrix metalloproteinase- 9 undergoes expression and activation during dendritic remodeling in adult hippocampus. J Neurosci 22:920-930.

Tanaka H, Shan W, Phillips GR, Arndt K, Bozdagi O, Shapiro L, Huntley GW, Benson DL, Colman DR (2000) Molecular modification of N-cadherin in response to synaptic activity. Neuron 25:93-107.

Togashi H, Abe K, Mizoguchi A, Takaoka K, Chisaka O, Takeichi M (2002) Cadherin regulates dendritic spine morphogenesis. Neuron 35:77-89.

Tomimatsu Y, Idemoto S, Moriguchi S, Watanabe S, Nakanishi H (2002) Proteases involved in long-term potentiation. Life Sci 72:355-361.

Toni N, Buchs PA, Nikonenko I, Povilaitite P, Parisi L, Muller D (2001) Remodeling of synaptic membranes after induction of long-term potentiation. J Neurosci 21:6245-6251.

VanSaun M, Werle MJ (2000) Matrix metalloproteinase-3 removes agrin from synaptic basal lamina. J Neurobiol 43:140-149.

Vu TH, Werb Z (2000) Matrix metalloproteinases: effectors of development and normal physiology. Genes Dev 14:2123-2133.

Wang P, Wang X, Pei D (2004) Mint-3 regulates the retrieval of the internalized membrane-type matrix metalloproteinase, MT5-MMP, to the plasma membrane by binding to its carboxyl end motif EWV. J Biol Chem 279:20461-20470.

Wang X, Pei D (2001) Shedding of membrane type matrix metalloproteinase 5 by a furin-type convertase: a potential mechanism for downregulation. J Biol Chem 276:35953-35960.

Wang X, Yi J, Lei J, Pei D (1999) Expression, purification and characterization of recombinant mouse MT5-MMP protein products. FEBS Lett 462:261-266.

Wang X, Lee SR, Arai K, Tsuji K, Rebeck GW, Lo EH (2003) Lipoprotein receptor-mediated induction of matrix metalloproteinase by tissue plasminogen activator. Nat Med 9:1313-1317.
Wright JW, Kramar EA, Meighan SE, Harding JW (2002) Extracellular matrix molecules, long-term potentiation, memory consolidation and the brain angiotensin system. Peptides 23:221-246.

Wright JW, Masino AJ, Reichert JR, Turner GD, Meighan SE, Meighan PC, Harding JW (2003) Ethanol-induced impairment of spatial memory and brain matrix metalloproteinases. Brain Res 963:252-261.

Wu YP, Siao CJ, Lu W, Sung TC, Frohman MA, Milev P, Bugge TH, Degen JL, Levine JM, Margolis RU, Tsirka SE (2000) The tissue plasminogen activator (tPA)/plasmin extracellular proteolytic system regulates seizureinduced hippocampal mossy fiber outgrowth through a proteoglycan substrate. J Cell Biol 148:1295-1304.

Wyszynski M, Kim E, Dunah AW, Passafaro M, Valtschanoff JG, Serra-Pages C, Streuli M, Weinberg RJ, Sheng M (2002) Interaction between GRIP and liprin-alpha/SYD2 is required for AMPA receptor targeting. Neuron 34:39-52.

Yamagata M, Sanes JR, Weiner JA (2003) Synaptic adhesion molecules. Curr Opin Cell Biol 15:621-632.

Yamazaki M, Fukaya M, Abe M, Ikeno K, Kakizaki T, Watanabe M, Sakimura K (2001) Differential palmitoylation of two mouse glutamate receptor interacting protein 1 forms with different $\mathrm{N}$-terminal sequences. Neurosci Lett 304:81-84.

Yong VW, Power C, Forsyth P, Edwards DR (2001) Metalloproteinases in biology and pathology of the nervous system. Nat Rev Neurosci 2:502-511.

Yuste R, Bonhoeffer T (2001) Morphological changes in dendritic spines associated with long-term synaptic plasticity. Annu Rev Neurosci 24:1071-1089.

Zhang JW, Deb S, Gottschall PE (1998) Regional and differential expression of gelatinases in rat brain after systemic kainic acid or bicuculline administration. Eur J Neurosci 10:3358-3368.

Zhang Q, Fan JS, Zhang M (2001) Interdomain chaperoning between PSD95, Dlg, and Z0-1 (PDZ) domains of glutamate receptor-interacting proteins. J Biol Chem 46:43216-43220.

Ziff EB (1997) Enlightening the postsynaptic density. Neuron 19:1163-1174. 